
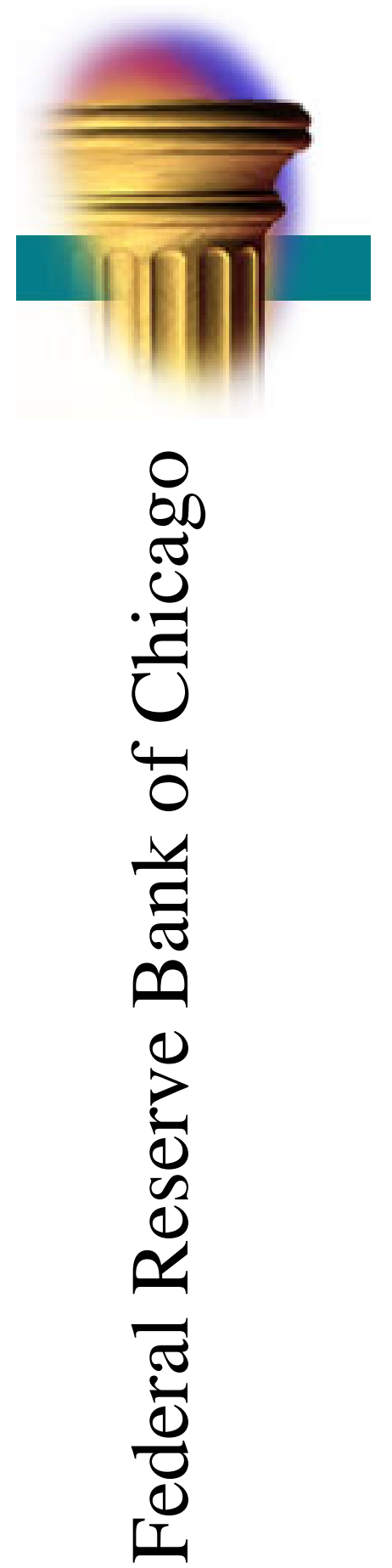

The Interplay Between Financial Conditions and Monetary Policy Shocks

Marco Bassetto, Luca Benzoni, and Trevor Serrao

October 2016

WP 2016-11 


\title{
The Interplay Between Financial Conditions and Monetary Policy Shocks *
}

\author{
Marco Bassetto, ${ }^{\dagger}$ Luca Benzoni, ${ }^{\ddagger}$ and Trevor Serrao ${ }^{\S}$
}

First draft: March 2, 2016

This draft: October 17, 2016

\begin{abstract}
We study the interplay between monetary policy and financial conditions shocks. Such shocks have a significant and similar impact on the real economy, though with different degrees of persistence. The systematic fed funds rate response to a financial shock contributes to bringing the economy back towards trend, but a zero lower bound on policy rates can prevent this from happening, with a significant cost in terms of output and investment. In a retrospective analysis of the U.S. economy over the past 20 years, we decompose the realization of economic variables into the contributions of financial, monetary policy, and other shocks.
\end{abstract}

${ }^{*}$ We are extremely grateful to Egon Zakrajšek for sharing the updated excess bond premium series with us. We thank Andrea Ajello, Gadi Barlevy, Mariacristina De Nardi, Charlie Evans, Jonas Fisher, Alejandro Justiniano, Spencer Krane, Leonardo Melosi, and Anna Paulson for comments and suggestions and Martin Eichenbaum for sharing code. All remaining errors are our own. The views expressed herein are those of the authors and not necessarily those of the Federal Reserve Bank of Chicago or the Federal Reserve System.

The most recent version of this article is available at http://ssrn. com/abstract=2852483.

${ }^{\dagger}$ Federal Reserve Bank of Chicago and University College London, bassetto@nber.org

${ }_{\ddagger}^{\ddagger}$ Federal Reserve Bank of Chicago, lbenzoni@frbchi.org

$\S$ Federal Reserve Bank of Chicago, tserrao@frbchi.org 


\section{Introduction}

Disruptions in financial markets have been identified as a major source of business cycle fluctuations. ${ }^{1}$ The role of financial shocks in driving macroeconomic performance has received even greater attention since the Great Recession. ${ }^{2}$

Our goal is to focus more on the interplay between financial conditions and monetary policy. Three key questions motivate our exercise. First, how does the magnitude of financial shocks compare with that of monetary policy shocks in driving macroeconomic fluctuations? Second, how large is the systematic response of monetary policy when a financial shock hits? Third, how different is the impact of a financial shock if monetary policy does not respond to it, as might be the case when interest rates hit the zero lower bound?

We explore these questions using evidence from vector autoregressions, looking across two widely used specifications that have become prominent in identifying monetary and financial shocks. In our baseline, we adopt the excess bond premium index constructed by Gilchrist and Zakrajšek [24] (EBP from now on), which summarizes particularly well the financial conditions that are predictive of future output, and follow their identification strategy. ${ }^{3}$ As an alternative, we augment the VAR from Christiano, Eichenbaum, and Evans [13]. In this case, the original paper did not directly include a measure of financial conditions, so we

\footnotetext{
${ }^{1}$ On the empirical front, examples of this large literature are Friedman and Kuttner [18, 19], Bernanke, Gertler, and Gilchrist [4], Emery [16], Gertler and Lown [21], Gilchrist, Yankov, Zakrajšek [23], Gilchrist and Zakrajšek [24], and Faust et al. [17]. Theoretical underpinnings for this empirical work can be found in Bernanke and Gertler [5], Kiyotaki and Moore [31], Carlstrom and Fuerst [11], Bernanke, Gertler, and Gilchrist [6], Cooley and Quadrini [14], Jermann and Quadrini [30, 29] and Bassetto, Cagetti, and De Nardi [3], among many others.

${ }^{2}$ In the empirical literature, Adrian, Moench, and Shin [1] look at the balance sheet of financial intermediaries and its relation with financial shocks; Hubrich and Tetlow [28] explore nonlinear specifications and find that a Markov-switching regime shift performs better when financial conditions are measured using an alternative measure of financial stress adopted by the Federal Reserve Board; and Caldara et al. [8] try to disentangle financial shocks from uncertainty shocks. Further theoretical work has explored in particular the role of information asymmetries in amplifying financial shocks; see e.g. Kurlat [32], Guerrieri and Shimer [27], and Bigio [7]. Christiano, Motto, and Rostagno [12] have introduced financial frictions in a large-scale dynamic stochastic general-equilibrium model. Ajello [2] has developed a smaller-scale model that incorporates microeconomic information. In his model, shocks to the intermediation spread account for about a quarter of the variation in GDP and investment.

${ }^{3}$ This measure has been found to be useful in European countries as well; see Gilchrist and Mojon [22].
} 
augment the original VAR by including the EBP index. A difficulty in identifying shocks from short-run restrictions lies in the fact that both credit spreads and short-term interest rates could react contemporaneously to monetary policy and credit shocks. We thus experiment with ranking either shock first in the Cholesky decomposition; our results turn out to be robust to either ordering. ${ }^{4}$

Based on our estimation, one-standard-deviation shocks to financial conditions and monetary policy have comparable effects on output. However, consistent with the traditional view that monetary policy is subject to long (and perhaps variable) lags, the effect of financial conditions on GDP peaks earlier and dies out faster than that of monetary policy. There is also some evidence that financial conditions may have a somewhat larger effect on business fixed investment than monetary policy. The fact that financial shocks have a disproportionate effect on investment is consistent with the view that firms are particularly subject to financial frictions.

In relation to our second question, monetary policy responds to financial shocks by leaning against the wind. This response occurs only gradually, even in specifications in which monetary policy is allowed to respond immediately, but it is significant for a period that extends well beyond the original shock to financial conditions. At its peak, the response to a one-standard deviation shock to excess bond premia (20 basis points) is almost as large as that of a one-standard deviation shock to monetary policy itself (about 50 basis points). This response is a likely factor in hastening the return of output to trend, compared to what happens when a long-lived monetary disturbance takes place.

In the current environment of very low nominal interest rates, the systematic response described above may be impossible if a contractionary shock to financial conditions hits. It is then interesting to inquire how differently the economy would evolve in such a scenario. As is the case with other papers that have studied the zero lower bound in linear VARs, ${ }^{5}$ we neutralize the response of monetary policy by positing a sequence of fed funds rate shocks

\footnotetext{
${ }^{4}$ Using high-frequency data to identify monetary policy shocks, Gertler and Karadi [20] find a bigger effect of monetary policy on excess bond premia. Their paper is concerned about monetary policy shocks alone and does not identify financial shocks. In a recent working paper, Caldara and Herbst [9] use Gertler and Karadi's approach in a Bayesian SVAR that includes financial shocks; similarly to us, they find that there is a systematic response of monetary policy to financial shocks, but they do not consider the potential implications when monetary policy is not allowed to respond.

${ }^{5}$ See e.g. Campbell et al. [10] or Del Negro, Giannoni, and Patterson [15]
} 
that will exactly offset the systematic deviations from trend that the VAR would otherwise predict. The difference between this case and our baseline does not manifest itself for the first year: this is both because monetary policy responds only gradually in the baseline, and because its effect on output and investment is delayed in turn. As time passes, the impulse responses with and without reactions in the fed funds rate diverge considerably. The peak output deviation from trend is $50 \%$ bigger and occurs two years later when policy rates remain fixed; moreover, reversion to trend is much slower. These results underscore the stabilizing effect of monetary policy and quantify the degree by which an economy at the zero lower bound is more exposed to disruptions in financial markets.

To put these numbers further in perspective, we reinterpret the experience of the past 20 years through the lens of our VAR exercise, a period characterized by unusual movements in financial conditions. We decompose the evolution of GDP and investment into the components accounted for by the VAR shocks. Across episodes, we consistently find that financial shocks are a driving force; nonetheless, the fraction of movement that they explain exhibits considerable variation. Financial shocks account for almost all of the 2001 recession, but even the exceedingly large shocks of 2008 only account for about half of the subsequent decline, with some evidence that the zero lower bound exacerbated the downturn. Easy financial conditions were a major factor in the expansion of the late 1990s, but the model suggests that shocks other than to the excess bond premium of Gilchrist and Zakrajšek and to the federal funds rate were responsible for the events of 2005-2007.

The rest of the article proceeds as follows. In Section 2, we lay out the baseline VAR model and some alternative specifications. The next three sections answer the main questions of the paper: First, we study the effects of monetary policy and financial shocks (Section 3); next we investigate the monetary policy response to a financial shock (Section 4); then we examine the impact of a financial shock when the systematic monetary policy response is neutralized (Section 5). In Section 6, we interpret the experience observed during two periods of easy financial conditions and the two subsequent episodes of sharp financial contractions through the lens of our VAR exercise. Section 7 concludes with ideas for future work. 


\section{The Baseline Model}

To study the effects of monetary policy and financial conditions shocks, we consider a VAR model

$$
Y_{t}=\mu+\sum_{i=1}^{N} \Phi_{i} Y_{t-i}+\Sigma \varepsilon_{t},
$$

with $N=4$ quarterly lags and a vector of independent and identically distributed (i.i.d.) shocks $\varepsilon$ that has Gaussian distribution $N(0, I)$, where $I$ is an identity matrix. In our baseline specification, we follow Gilchrist and Zakrajšek [24] and include in the state vector $Y$ (i) the log-difference of real personal consumption expenditures (PCE); (ii) the log-difference of real business fixed investment (BFI); (iii) the log-difference of real GDP; (iv) inflation as measured by the log-difference of the GDP price deflator; (v) a measure of financial conditions (FC); (vi) the quarterly (value-weighted) excess stock market return; (vii) the ten-year (nominal) Treasury yield; and (viii) the effective nominal federal funds rate (FFR) ${ }^{6}$

Our baseline specification uses the excess bond premium of Gilchrist and Zakrajšek [24] as a measure of financial conditions, incorporating the new data since their publication. ${ }^{7}$ For identification, we specify $\Sigma$ to be a lower triangular matrix. That is, we assume that economic quantities do not respond contemporaneously to a shock in financial variables. In contrast, monetary policy responds contemporaneously to a financial condition shock, as well as to shocks to the other variables in the system. We use this as a baseline to follow Gilchrist and Zakrajšek [24]; this specification attributes all trend deviations in financial variables that are not accounted for by real disturbances to financial shocks. We will also experiment with the opposite ordering (see below).

We estimate the VAR model (1) by ordinary least squares (OLS) over the sample period from 1974Q2 to 2016Q1. We then compute impulse response functions (IRFs) and obtain their $90 \%$ confidence bands with a simulation approach that relies on drawing 1,000 sets of model coefficients from their asymptotic distribution.

\footnotetext{
${ }^{6}$ Stock market return data source: CRSP ${ }^{\circledR}$, Center for Research in Security Prices, Booth School of Business, The University of Chicago. Used with permission. All rights reserved. crsp.uchicago.edu. Source for the other data: Haver.

${ }^{7}$ We are extremely grateful to Egon Zakrajšek for sharing the updated excess bond premium series with us.
} 


\subsection{Robustness Checks}

\subsubsection{Model Specification}

As an alternative to the baseline model, we augment the VAR of Christiano, Eichenbaum, and Evans [13] to include a measure of financial conditions. We define the state vector $Y_{t}$ to include (i) the log real gross domestic product; (ii) the log real consumption; (iii) the log GDP deflator; (iv) the log real investment; (v) the log real wage; (vi) the log labor productivity; (vii) FC; (viii) the FFR; (ix) the log real profits; and (x) the growth rate of M2 (data source: Haver). This choice of variables is identical to Christiano, Eichenbaum, and Evans [13], except for the addition of FC ordered right before the FFR. This specification differs from the baseline VAR in that it includes variables that are non-stationary. We maintain the identification assumption that $\Sigma$ is lower triangular, i.e., the economic variables (i)-(vi) do not respond contemporaneously to other shocks in the system, monetary policy surprises respond to shocks in economic variables as well as financial conditions, and FC innovations do not respond to monetary policy shocks. We choose to consider this alternative specification both because of its prominence among research on the effects of monetary policy shocks and because the level specification might contain some extra information through possible cointegrating relationships. We label this model specification as CEE in what follows.

\subsubsection{Financial Conditions Measures}

We confirm below that our main findings are robust to alternative measures of financial conditions, such as the Chicago Fed National Financial Conditions Index (NFCI) and Moody's Baa corporate bond spread over the 10-year Treasury computed using data from the H.15 data release of the Federal Reserve Board. In particular, the EBP index and the Baa-Treasury spreads focus on corporate financing conditions, while the NFCI is a broader measure which includes additional information that might be relevant for small firms and consumers, such as bank lending standards and delinquency rates.

\subsubsection{Sample Period}

Our baseline sample starts in 1974Q2. Since monetary policy is an important piece of our analysis, it is of independent interest to see how the results change during the more stable 
period that excludes the initial high inflation and Volcker's disinflation. To this end, we consider a shorter 1985Q1-2016Q1 sample.

\subsubsection{Alternative Ordering}

In the baseline case, financial conditions are assumed not to respond to monetary shocks contemporaneously. Using high-frequency data, Gertler and Karadi [20] do find such a response. We thus experiment with reversing the order of financial and monetary policy shocks in the Cholesky decomposition; this alternative gives more prominence to monetary policy shocks. Most of our results are independent of this ordering, which gives us confidence in drawing inference about the effects of the two shocks.

\section{The Effects of Monetary Policy and Financial Shocks}

Figure 1 shows impulse response functions for the baseline model for log-GDP, log-BFI, financial conditions, and the federal funds rate to expansionary shocks in financial conditions (left panels) and monetary policy (right panels). ${ }^{8}$ Similar to Gilchrist and Zakrajšek [24], a one-standard-deviation easing in financial conditions leads to a significant improvement in economic variables, with a 46 basis points peak increase in GDP above its trend five quarters after the FC shock impact. Investment shows an even bigger jump, with BFI peaking 235 bps above its trend approximately two years after the FC shock.

At its peak, the effect of a one-standard-deviation monetary policy shock is similar: GDP and BFI rise 52 and 179 basis points above trend, respectively. While monetary policy is slightly more powerful on output (a one standard-deviation FFR shock is equivalent to a 1.15 FC shock), the reverse is true for investment (where a standardized FC shock is $30 \%$ more powerful). ${ }^{9}$ This discrepancy is consistent with the view that the excess bond premium captures conditions that are particularly relevant for the corporate sector and thus impacts

\footnotetext{
${ }^{8}$ Impulse response functions for the other variables in $Y$ are in Figure 2. For log-GDP, log-BFI, logconsumption, and the excess market return, we cumulate the responses over time.

${ }^{9}$ Based on these numbers, a 100-basis-point unexpected improvement in financial conditions has a peak impact roughly equivalent to an unexpected 226-basis-point monetary policy easing for GDP and a 340-basispoint easing for investment. The standard deviation of financial conditions and monetary policy shocks is 22 and 57 bps.
} 
the economy primarily through the investment margin, whereas monetary policy shocks operate through broader channels as well.

A second difference between the two shocks concerns their time profile. An FFR decline is slower to act, especially on BFI which does not exhibit a significant increase for nearly two years. Once the effects manifest themselves, they persist considerably longer. Starting from the own-variable response, the excess bond premium returns to its steady state value within two years of an FC shock, while the fed funds rate is significantly affected by an FFR shock for at least two and a half years, and the point estimate remains negative throughout the five-year window. Monetary policy shocks have a more persistent impact on real variables as well: GDP and BFI peak about three and four years after the shock, respectively, and their levels remain statistically above trend for more than five years.

Table 1 shows another measure of the relative importance of financial and monetary shocks, by decomposing the variance of the forecasting error of our main variables of interest into the contribution of the different shocks. For GDP, financial shocks account for a greater fraction of the variance relative to FFR shocks, especially at short horizons, since the effect of FFR innovations builds more gradually over time. The same pattern emerges for investment, except that, as noted in the impulse response functions, FC disturbances account for an even bigger fraction of the variation.

Figure 3 (and Table 3 in the online appendix) illustrates similar results when financial conditions are measured by the NFCI. The conclusions still hold, but the impact of an FC shock is somewhat muted compared to the baseline case. The impulse response functions following an FC shock peak at 37 and 121 bps above trend for GDP and BFI, respectively, while the effect of monetary policy shocks matches the baseline results. In relative terms, while FC shocks were more powerful on investment under the baseline EBP measure, this is no longer the case with the broader NFCI. We also perform a similar exercise using the Baa-Treasury spread as an FC measure. The results, in Figure 4, are in line with those that we have discussed here for the NFCI, although the responses of output and investment to FC shocks are even smaller. Overall, these findings support the Gilchrist and Zakrajšek [24] conclusion that the excess bond premium is a more powerful predictor of future activity, especially investment, than other financial variables.

Figure 5 presents results for the VAR model inspired by Christiano, Eichenbaum, and Evans [13], augmented to include the excess bond premium as a measure of financial con- 
ditions. In this alternative specification, the impact of monetary policy on GDP is nearly identical to what we have obtained in the baseline case. The peak effect of an FFR shock on investment is slightly smaller than the effect on BFI in the baseline model, but the time profile looks similar. Turning next to financial conditions, as in the baseline case Figure 5 shows that FC shocks have a significant impact on GDP and investment, though their magnitude is somewhat weaker. IRFs exhibit a similar pattern, with the peak occurring roughly at the same time; nonetheless, mean reversion is complete in the CEE specification and only partial in our baseline. This discrepancy is given prominence in the variance decomposition (Table 2): in the CEE specification, FC shocks account for a smaller fraction of the unconditional variance of GDP and investment (right-most column). At business-cycle frequencies, the difference between the two specifications is limited.

Figure 6 repeats the analysis using the sample period from 1985Q1 to 2016Q1. Over this shorter window, the standard deviation of FC shocks remains almost the same. In contrast, FFR shocks are about 63\% smaller (the standard deviation drops from 57 to 21 bps). That monetary shocks become much smaller in this period is precisely why we chose to run this robustness check. Since Figure 6 plots the impulse response functions following a one-standard-deviation shock, the corresponding effect on GDP and BFI of an FFR shock is muted over this shorter sample. Nonetheless, for a given-size shock (say, 100bps), the point estimates of the response over this shorter span are fairly similar to those we obtain in our baseline case. The smaller shocks and shorter time series contribute to lowering the precision of the estimates, which are no longer significant. In regards to financial conditions, we find consistent results for all variables across the two samples.

Finally, the results are unchanged in the alternative Cholesky odering in which FFR shocks can have an immediate effect on financial conditions (Figure 7).

\section{The Monetary Policy Response to a Financial Shock}

Figure 1 also shows that monetary policy responds to financial conditions, with the expected sign: an easing of financial conditions leads to a tightening of policy, albeit one that is insufficient to completely stabilize output and investment. The FFR peaks around 50 basis points above steady state one to two years out. Although in this identification scheme the FFR is allowed to respond on impact to shocks to financial conditions, the magnitude of the 
immediate response turns out to be very small. Table 1 shows that FC innovations account for almost none of the variance of the fed funds rate at a one-year horizon, but build to $20 \%$ of its variance three years out.

In sum, policymakers react to FC shocks with gradual changes in the FFR. The response persists for several years, with a peak $(50 \mathrm{bps})$ that is equivalent to a 0.87 standard-deviation FFR shock. In terms of response in output, we have established in Section 3 above that such an FFR surprise is equivalent to a one-standard-deviation FC shock. Hence, our results suggest that monetary policy leans against the wind in an attempt to undo the effect of FC on output.

When we replace the EBP measure of financial conditions with either the NFCI or the Baa-Treasury spread, a response of the FFR on impact emerges, but it is positive in the case of the Baa-Treasury spread (Figure 4) and negative when financial conditions are measured by the NFCI (Figure 3). After the initial few quarters, the three models based on different FC proxies display a consistent pattern, with monetary policy counteracting unexpected changes in financial conditions. ${ }^{10}$

The stabilizing effect of monetary policy on the economy is robust to the alternative CEE specification (Figure 5), to the post-1985 sample period (Figure 6), and to the alternative Cholesky ordering in which the FFR is not allowed to respond on impact (Figure 7).

\section{The Impact of a Financial Shock when Monetary Policy Does not Respond}

Given that monetary policy plays a significant role in buffering financial shocks, it is interesting to inquire what would happen if policymakers were unwilling or unable to intervene, as might be the case when policy rates are close to the zero lower bound (ZLB). A complete answer to this question would require a fully microfounded model, where the interplay between the zero lower bound and private sector expectations can be explicitly accounted for. Here instead we adopt an approach used in several other papers (e.g., Campbell et al. [10] or Del Negro, Giannoni, and Patterson [15]) and we assume that a sequence of monetary

\footnotetext{
${ }^{10}$ The effect remains smaller and thus not statistically significant when NFCI is used as an FC measure.
} 
shocks follows the initial FC shock in such a way as to keep the fed funds rate constant. ${ }^{11}$ We then look at how the economy responds to the combination of these shocks.

Figure 8 presents results from our baseline specification, where we contrast the response of the economy to an FC shock when monetary policy follows its systematic response (blue line) and when it is neutralized by the suitable sequence of shocks (red line). ${ }^{12}$ As we discussed in the previous section, the systematic FFR response picks up over time (lower-right panel). Furthermore, as was shown in Figure 1, FFR shocks themselves have a gradual effect on GDP and investment. Hence, the blue and red lines track each other closely for the first year. From then on, the red line departs considerably from the systematic path. When monetary policy leans against the wind (blue line), output and investment flatten out soon after the first year, reach their peak within a couple of quarters, and start reverting to trend thereafter. In contrast, when the FFR is fixed, output and investment continue to grow for about two more years, reaching a peak that is $50 \%$ and $25 \%$ higher for output and investment, respectively. We know from previous sections that FFR shocks have a comparatively larger effect than FC shocks on output rather than investment, which explains why neutralizing them shows up in GDP more than in investment. When the FFR does not move, reversion to trend occurs much more slowly, and it has barely started by the end of our five-year window.

When an expansionary FC shock is followed by the systematic FFR response, financial conditions overshoot their steady state and become tight in the second half of our window (Figure 8, lower-left panel). This contributes to the mean reversion in GDP and investment over that period. In contrast, when the FFR does not move, financial conditions still revert quickly to their steady state, but if anything they remain slightly accommodative throughout. The initial expansionary FC shock then propagates more fully through the economy.

Figure 9 shows how results change when we adopt the CEE specification. The pattern of divergence between the blue and red lines is the same as we observe in the baseline case. When the FFR response is neutralized, it is still the case that mean reversion in output and investment has barely started after five years.

We discussed in Section 3 that monetary policy appears to have a smaller effect when we

\footnotetext{
${ }^{11}$ Yet another alternative would be to move away from a linear statistical specification and adopt a Markovregime switching model. However, there are only eight years of data at the ZLB, which would be very unsatisfactory to identify the economy's response to shocks in that regime.

${ }^{12}$ In the lower right panel, the red line does not appear since the FFR remains at zero by design.
} 
restrict our attention to the post-1985 sample. It is thus not surprising that, in this sample, the divergence between the blue and red line is reduced, although its qualitative pattern remains the same (see Figure 10).

Figures 11 and 12 explore the consequences of adopting other measures of financial conditions. When we use the Baa-Treasury spread, the divergence between red and blue lines is magnified, because in this case we estimated the systematic response of monetary policy to almost fully offset the effect of the shock. In contrast, with the NFCI, there is scant evidence of a systematic FFR response, and so neutralizing it has little effect: the blue and red lines are close together. We thus conclude that our baseline VAR with the EBP measure of financial conditions conveys an intermediate view of the stabilizing role of monetary policy and the consequences of its inability to play this role at the ZLB.

Finally, the alternative identification scheme ranking the FFR first yields almost identical results to our baseline and is thus relegated to the Online Appendix.

In all but one of these cases, we thus find that the ZLB contributes to generate instability in response to financial shocks. This is a factor that should be taken into account in evaluating the balance of risks when choosing a target inflation rate and maneuvering rates around zero.

\section{Financial and Monetary Policy Shocks: Significant Episodes}

To better illustrate the significance of our exercise, we reinterpret the experience of the past 20 years through the lens of our VAR exercise. This period is particularly interesting because it was characterized by unusual movements in financial conditions, which have been largely presented as a driving disturbance for the economy. During these years, two periods of easy financial conditions were followed by sharp financial contractions, with differing impacts on output and investment.

For each of the four episodes, we decompose the realizations of our series of interest into the contributions due to different shocks and compare the experienced deviations from trend with what would have happened if only FC or FFR innovations had occurred. ${ }^{13}$ Since our

\footnotetext{
${ }^{13}$ For this exercise, we report results only for our baseline specification. Other specifications are available
} 
baseline VAR specification uses log-differences for GDP, investment, and consumption, the effect of shocks and initial conditions on the level of these variables accumulates over time and never decays. To focus on the short-run dynamics, we start each episode by purging all variables of the effect of past shocks and initial conditions and only look at the contributions stemming from the subsequent history of estimated shocks.

Figures 13-16 show the results of this experiment within each of our four time frames. The blue line accounts for all the shocks arising from the beginning of our windows. ${ }^{14}$ The red and green lines isolate the effect of the FC and FFR shocks, respectively. Finally, the black line combines FC and FFR shocks.

\subsection{Q1-2000Q4: The Dot-Com Boom}

The first period we consider is the long expansion of the late 1990s, a period associated with strong technological change (the "dot-com boom"). Figure 13 shows our decomposition, starting with shocks of 1996Q1. The lower-left panel confirms that this was a period of easy finance, until the very end of our five-year window (which sets the premise of our next subperiod). Financial conditions alone account for about a quarter of the GDP deviation from trend and a third of investment (top panels). Based on our estimates, monetary policy should have responded by tightening rates; more precisely, the red line in the bottom-right panel quantifies this predicted response in excess of $2 \%$ at the peak. In contrast, the green line in the same panel suggests that monetary policy was slow to act during this period. ${ }^{15}$ This is consistent with Fed Chairman Greenspan's view that the expansion was due to "a pickup in the growth of labor productivity-beyond the effects of the business cycle." (Greenspan [26]). ${ }^{16}$ As a result of this, monetary policy further contributes to the expansion, although less than financial and other shocks.

\footnotetext{
upon request.

${ }^{14}$ The sum of the blue line and the previously accumulated shocks and initial conditions returns the actual data realization of each series.

${ }^{15}$ Given the strong expansion emerging in our top panels, the other shocks would also have called for additional monetary tightening, whereas the blue line is close to the red one.

${ }^{16}$ The 1999 speech offers a retrospective on the period. For an early account of Greenspan's belief in the potential of new technologies, see Greenspan [25].
} 


\subsection{Q2-2005Q1: The 2001 Recession and its Aftermath}

Figure 14 picks up the tightening that occurs at the end of the previous window and studies the effects from there onwards. Shocks to financial conditions account for all of the 2001 recession for both output and investment. The recovery is held back both by a second bout of FC tightening in 2002 (red line, bottom-left panel) and by the fact that, throughout the period, monetary policy was not as easy as called for by other shocks (green line, bottomright panel). Taken together, the FC and FFR shocks account well for the evolution of GDP (black line, top-left panel). The same is true for investment, except for the tail end of the period, in which other shocks contribute to a slow recovery (top-right panel), setting the premise for our next episode.

\subsection{Q1-2007Q4: The Credit Boom}

The years between 2004 and 2006 are usually associated with loose credit standards, which then contributed to losses in the financial intermediation sector and the subsequent crisis in 2008. Our VAR confirms that this was a period of easy financial conditions. However, quantitatively, this easing is less dramatic than what was observed in the late 1990s. Here, it is important to stress that Gilchrist and Zakrajšek's index of financial conditions is based on corporate bond spreads and does not directly capture the extension of credit to the private sector, especially to individuals and firms with weaker credit ratings.

In contrast to the previous period, the path of GDP and investment implied by FC shocks is far away from the small negative deviations from trend represented by the blue lines in the top panel of Figure 15. For most of this period, FFR shocks contribute little to the evolution of GDP and investment, with the green lines staying very close to zero. While at the very beginning of this window they tend to be accommodative, corresponding to the "slow march to neutral," they return to a neutral stance rather quickly and turn contractionary at the end. According to our VAR, other shocks are responsible for significant head winds, which might warrant future investigation of other contributing factors to the financial crisis and the Great Recession. 


\subsection{Q3-2013Q2: The Great Recession}

Our final period starts with the large contractionary FC shocks that occurred with the financial crisis at the end of 2008. The baseline VAR identifies three quarters in which FC shocks led to extremely tight conditions: the third quarter of 2008 through the first of 2009 (Figure 16, bottom-left panel). By the second quarter of 2009, the financial shocks captured by the excess bond premium index are back to neutral. It is likely that broader measures of financial conditions would reflect further tightness.

The large FC shocks predict a correspondingly steep decline in output and investment over the subsequent year and some persistent weakness thereafter. The actual decline in the GDP data (top-left panel) is twice as big as predicted by the red line, leaving substantial room for other shocks, including restrictive conditions in the financial sector beyond those captured by the EBP index. As times goes by, these other shocks become more important to fully account for the slow recovery. As we observed throughout this paper, the link between investment and financial conditions tends to be stronger; this episode is no exception, as FC shocks account for a larger share of the decline and also better track the (partial) recovery.

The bottom-right panel displays the accumulated effect of shocks on the fed funds rate. According to the systematic response, financial conditions alone would have called for a 300-basis-point easing over this period. Given that the average fed funds rate in the second quarter of 2008 was $2.1 \%$, this would of course have led to negative rates. As a result of the zero lower bound, monetary policy could not be as accommodative, which is reflected in the path of the green line: while the model estimates an easing early on in the fourth quarter of 2008 , by the time the economy reached the effective ZLB at the beginning of 2009, monetary shocks became a contributor to tight conditions. ${ }^{17}$ The inability to ease monetary policy as much as called for by the systematic response accounts for about a $1 \%$ gap in output and a $3 \%$ gap in investment in 2011-2012, which might appear deceptively small due to the severity of the recession.

\footnotetext{
${ }^{17} \mathrm{FFR}$ shocks lead the fed funds rate to be about $1 \%$ higher than it would otherwise have been, which is precisely the difference between the $3 \%$ implied by financial conditions and the 2 percentage points of margin of the ZLB that were left at the beginning of the period.
} 


\section{Conclusions}

In this paper, we conduct an empirical study of the interplay between monetary policy shocks and unexpected changes in financial conditions. Our main conclusions are that (1) one-standard-deviation FC and FFR shocks produce a statistically significant and similar impact on the real economy, though with different degrees of persistence. (2) Financial conditions and monetary policy react to each other. In particular, the systematic fed funds rate response to an $\mathrm{FC}$ shock contributes to bringing the economy back towards its trend at a faster pace. (3) However, a binding zero lower bound on policy rates can prevent policymakers from leaning against the wind, with a significant cost in terms of output and investment. We illustrate these three main conclusions in a retrospective analysis of the U.S. economy over the past 20 years, in which we decompose realization in the relevant economic variables into the contributions of FC, FFR, and other shocks.

We leave several other questions to future work. For instance,

- Gilchrist and Zakrajšek showed that shocks to excess premia on corporate bonds do particularly well at capturing the component of financial shocks that anticipates future macroeconomic conditions. It would be interesting to study in greater detail the channel through which these shocks propagate. Are these simply particularly clean measures of general financial conditions, or do shocks which originate in the corporate sector have a particularly powerful impact, compared with impairment in other segments of financial intermediation? Our analysis suggests that the decline in output during the Great Recession is considerably bigger than what is predicted by shocks to bond premia alone, leaving substantial room for other shocks. A challenge for future research is to better identify such shocks, and to build microfoundations to match the pattern of propagation at a more disaggregated level.

- A more thorough analysis of monetary policy and financial shocks when the fed funds rate is close to zero calls for a fully microfounded model, explicitly accounting for the interplay between the ZLB and private sector expectations. In this context, further work is also warranted to better understand how non-conventional monetary intervention, such as quantitative easing, acts and interplays with FC shocks. 


\section{References}

[1] Tobias Adrian, Emanuel Moench, and Hyun Song Shin. Financial Intermediation, Asset Prices, and Macroeconomic Dynamics. Staff Report 422, Federal Reserve Bank of New York, 2010.

[2] Andrea Ajello. Financial Intermediation, Investment Dynamics, and Business Cycle Fluctuations. American Economic Review, 106(8):2256-2303, 2016.

[3] Marco Bassetto, Marco Cagetti, and Mariacristina De Nardi. Credit crunches and credit allocation in a model of entrepreneurship. Review of Economic Dynamics, 18(1):53 $76,2015$.

[4] Ben Bernanke, Mark Gertler, and Simon Gilchrist. The Financial Accelerator and the Flight to Quality. Review of Economics and Statistics, 78(1):1-15, 1996.

[5] Ben S. Bernanke and Mark Gertler. Agency costs, net worth, and business fluctuations. American Economic Review, 79(1):14-31, 1989.

[6] Ben S. Bernanke, Mark Gertler, and Simon Gilchrist. The financial accelerator in a quantitative business cycle framework. volume 1, Part $\mathrm{C}$ of Handbook of Macroeconomics, chapter 21, pages 1341 - 1393. Elsevier, 1999.

[7] Saki Bigio. Endogenous Liquidity and the Business Cycle. American Economic Review, 105(6):1883-1927, 2015.

[8] Dario Caldara, Cristina Fuentes-Albero, Simon Gilchrist, and Egon Zakrajšsek. The macroeconomic impact of financial and uncertainty shocks. European Economic Review, 88:185-207, 2016.

[9] Dario Caldara and Edward Herbst. Monetary Policy, Real Activity, and Credit Spreads: Evidence from Bayesian Proxy SVARs. Finance and Economics Discussion Series 49, Federal Reserve Board, 2016.

[10] Jeffrey R. Campbell, Charles L. Evans, Jonas D.M. Fisher, and Alejandro Justiniano. Macroeconomic Effects of Federal Reserve Forward Guidance. Brookings Papers on Economic Activity, 2012(2):1-54, 2012. 
[11] Charles T. Carlstrom and Timothy S. Fuerst. Agency Costs, Net Worth, and Business Fluctuations: A Computable General Equilibrium Analysis. American Economic Review, 87(5):893-910, 1997.

[12] Lawrence Christiano, Roberto Motto, and Massimo Rostagno. Financial factors in economic fluctuations. Working Paper 1192, European Central Bank, 2010.

[13] Lawrence J. Christiano, Martin Eichenbaum, and Charles L. Evans. Nominal Rigidities and the Dynamic Effects of a Shock to Monetary Policy. Journal of Political Economy, 113(1):1-45, 2005.

[14] Thomas F. Cooley and Vincenzo Quadrini. Monetary Policy and the Financial Decisions of Firms. Economic Theory, 27(1):243-270, 2006.

[15] Marco Del Negro, Marc Giannoni, and Christina Patterson. The Forward Guidance Puzzle. Staff Report 574, Federal Reserve Bank of New York, 2012.

[16] Kenneth M. Emery. The Information Content of the Paper-Bill Spread. Journal of Economics and Business, 48(1):1-10, 1996.

[17] Jon Faust, Simon Gilchrist, Jonathan Wright, and Egon Zakrajšek. Credit Spreads as Predictors of Real-Time Economic Activity: A Bayesian Model-Averaging Approach. Review of Economics and Statistics, 95(5):1501-1519, 2013.

[18] Benjamin M. Friedman and Kenneth N. Kuttner. Money, Income, Prices, and Interest Rates. American Economic Review, 82(3):472-492, 1992.

[19] Benjamin M. Friedman and Kenneth N. Kuttner. Indicator Properties of the PaperBill Spread: Lessons from Recent Experience. Review of Economics and Statistics, 80(1):34-44, 1998.

[20] Mark Gertler and Peter Karadi. Monetary Policy Surprises, Credit Costs, and Economic Activity. American Economic Journal: Macroeconomics, 7(1):44-76, 2015.

[21] Mark Gertler and Cara S. Lown. The Information in the High-Yield Bond Spread for the Business Cycle: Evidence and Some Implications. Oxford Review of Economic Policy, 15(3):132-150, 1999. 
[22] Simon Gilchrist and Benoît Mojon. Credit Risk in the Euro Area. Working Paper 20041, NBER, 2014.

[23] Simon Gilchrist, Vladimir Yankov, and Egon Zakrajšek. Credit Market Shocks and Economic Fluctuations: Evidence from Corporate Bond and Stock Markets. Journal of Monetary Economics, 56:471-493, 2009.

[24] Simon Gilchrist and Egon Zakrajšek. Credit Spreads and Business Cycle Fluctuations. American Economic Review, 104(4):1692-1720, 2012.

[25] Alan Greenspan. Technological Advances and Productivity. url=https://www.federalreserve.gov/boarddocs/speeches/1996/19961016.htm, 10 1996. Speech at the 80th Anniversary Awards Dinner of the Conference Board, New York, New York.

[26] Alan Greenspan. The American Economy in a World Context. url=https://www.federalreserve.gov/boarddocs/speeches/1999/19990506.htm, $\quad 5$ 1999. Speech at the 35th Annual Conference on Bank Structure and Competition of the Federal Reserve Bank of Chicago, Chicago, Illinois.

[27] Veronica Guerrieri and Robert Shimer. Dynamic Adverse Selection: A Theory of Illiquidity, Fire Sales, and Flight to Quality. American Economic Review, 104(7):1875-1908, 2014.

[28] Kirstin Hubrich and Robert J. Tetlow. Financial stress and economic dynamics: The transmission of crises. Journal of Monetary Economics, 70:100-115, 2015.

[29] Urban Jermann and Vincenzo Quadrini. Macroeconomic Effects of Financial Shocks. American Economic Review, 102(1):238-271, 2012.

[30] Urban J. Jermann and Vincenzo Quadrini. Stock market boom and the productivity gains of the 1990s. Journal of Monetary Economics, 54(2):413-432, 2007.

[31] Nobuhiro Kiyotaki and John Moore. Credit cycles. Journal of Political Economy, 105(2):211-248, 1997.

[32] Pablo Kurlat. Lemons Markets and the Transmission of Aggregate Shocks. American Economic Review, 103(4):1463-1489, 2013. 
FC on GDP


FFR on GDP
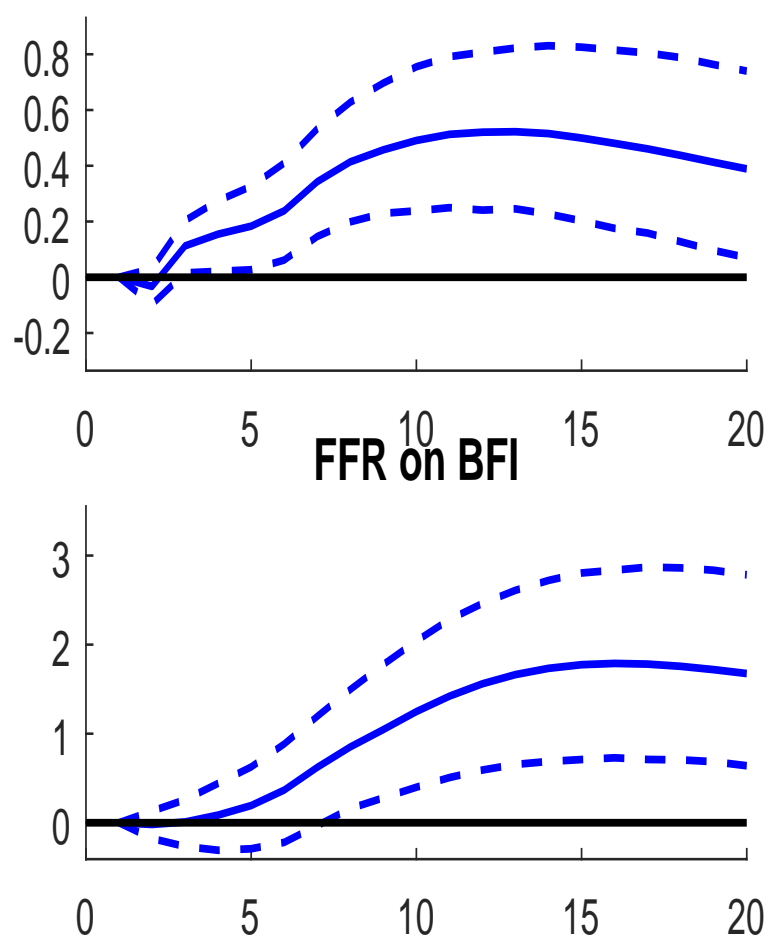

FFR on FC

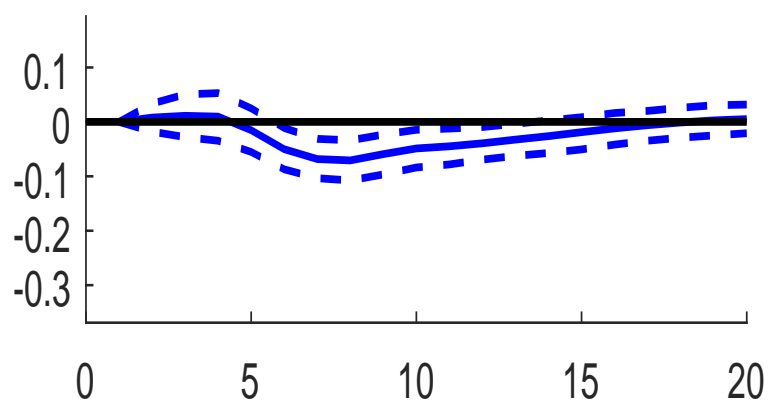

FFR on FFR

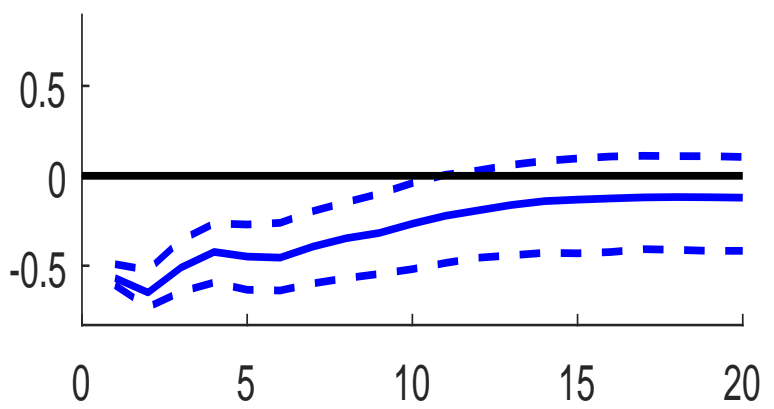

Figure 1: IRFs to FC and FFR Shocks IRFs and $90 \%$ confidence bands for the main variables of interest (GDP, BFI, FC, and FFR) are from the baseline VAR model in which financial conditions are measured by the excess bond premium. The sample period is 1974Q2-2016Q1. 

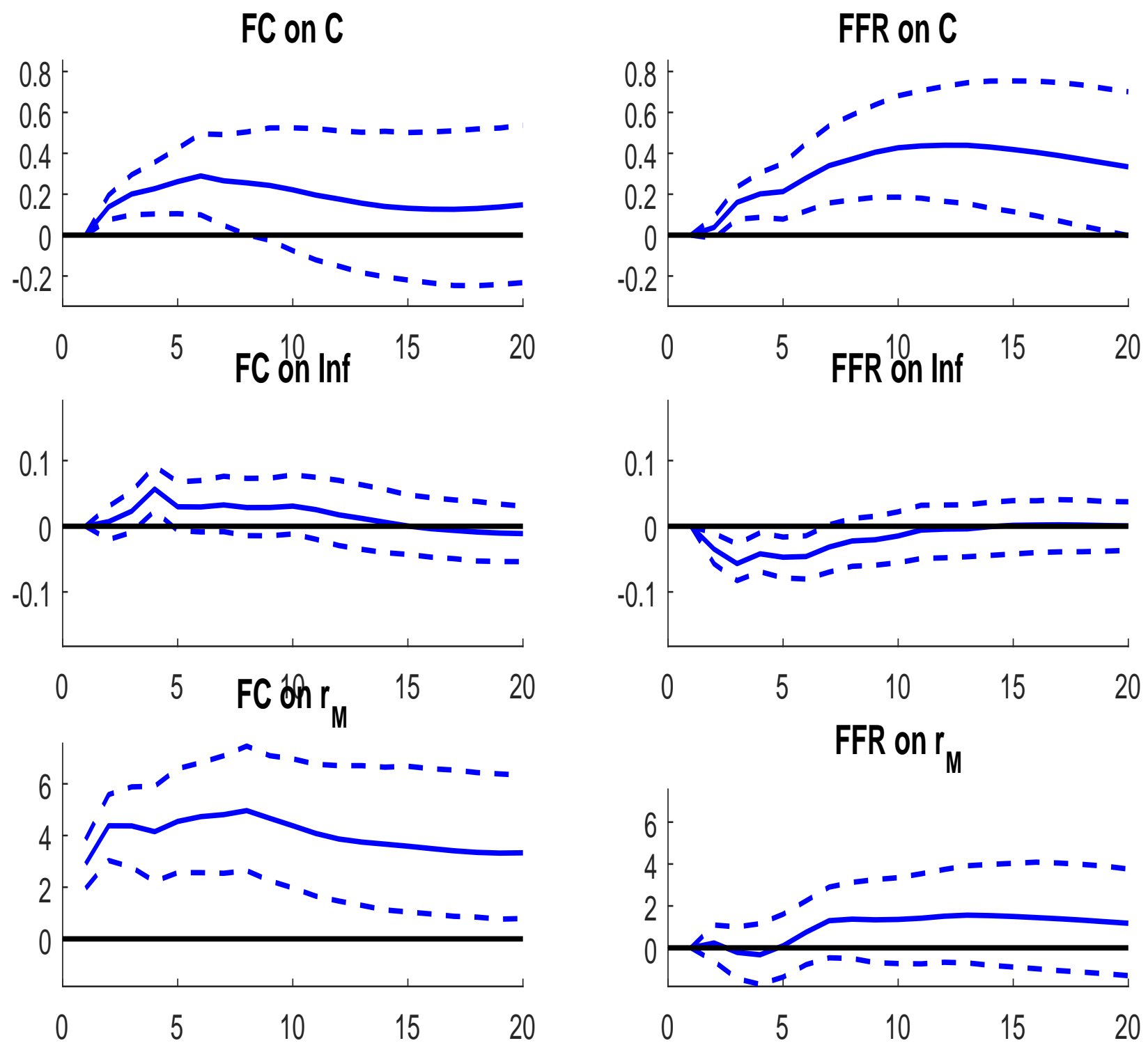

FFR on $r_{M}$

FC on CMT10

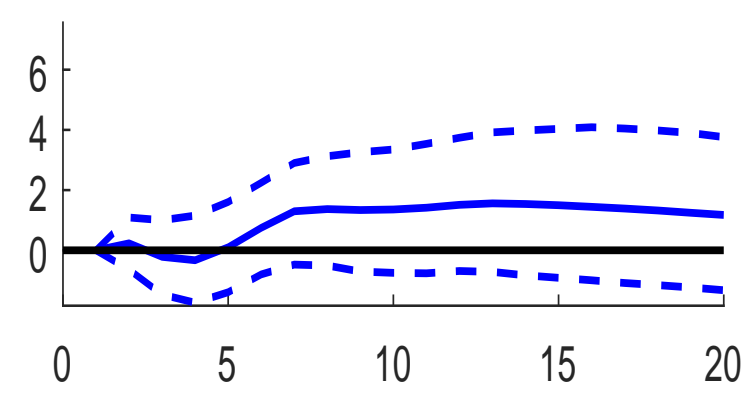

FFR on CMT10
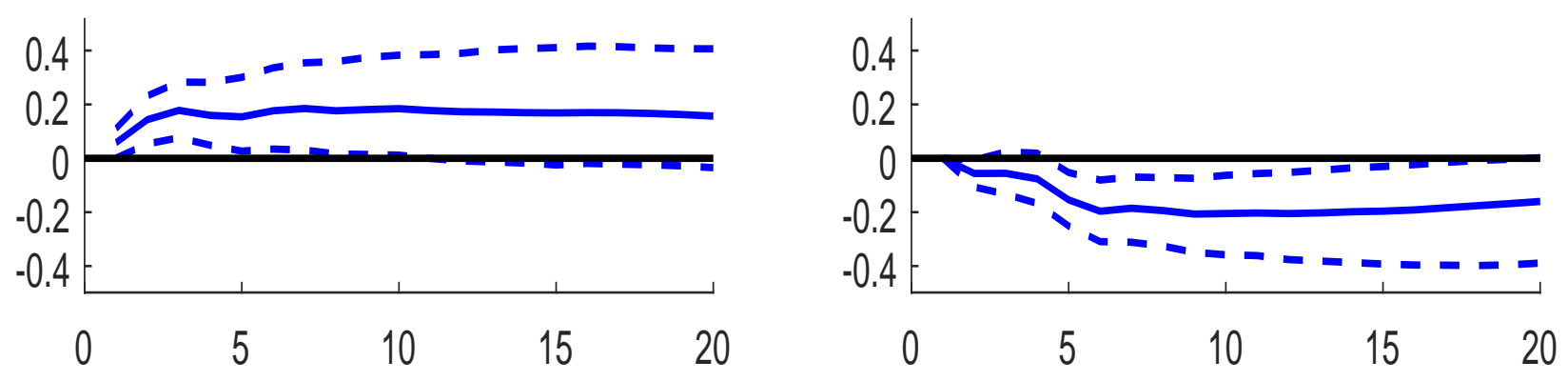

Figure 2: IRFs to FC and FFR Shocks IRFs and $90 \%$ confidence bands for consumption, inflation, excess market return, and 10-year Treasury rate are from the baseline VAR model in which financial conditions are measured by the excess bond premium. The sample period is 1974Q2-2016Q1. 
FC on GDP
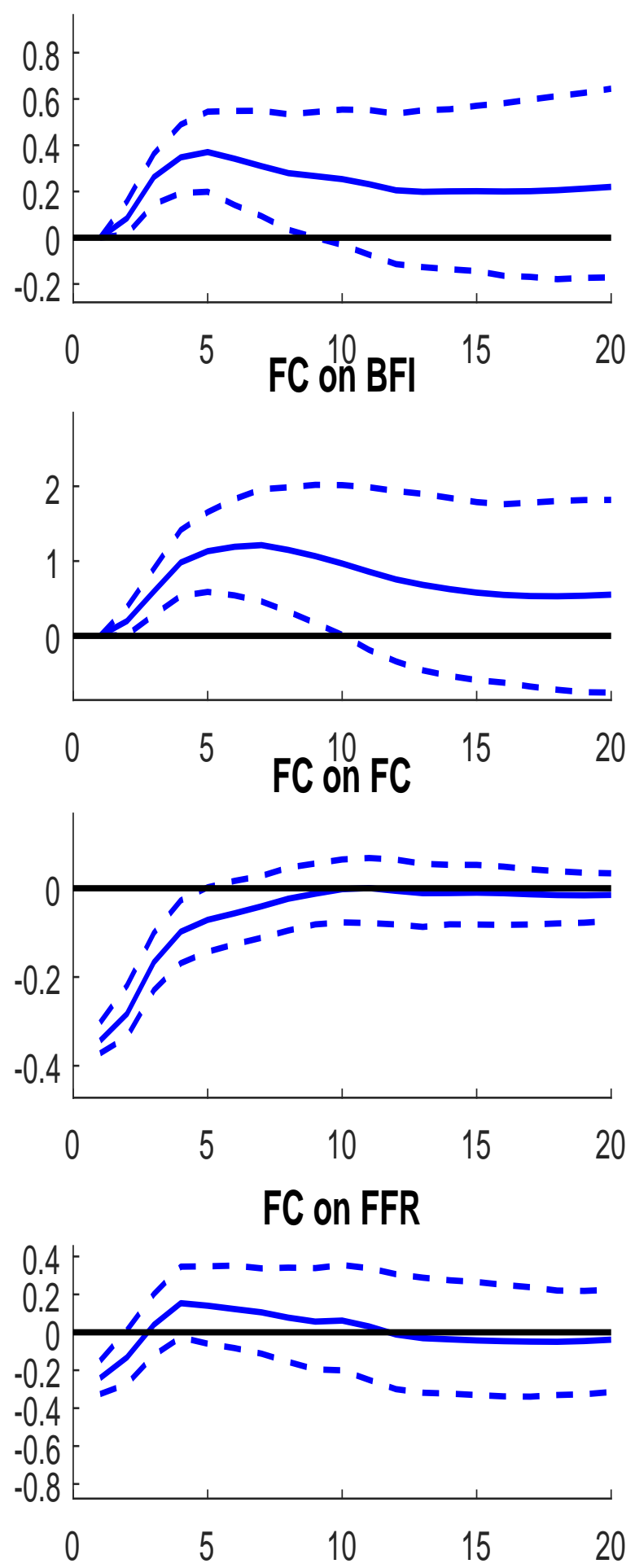

FFR on GDP
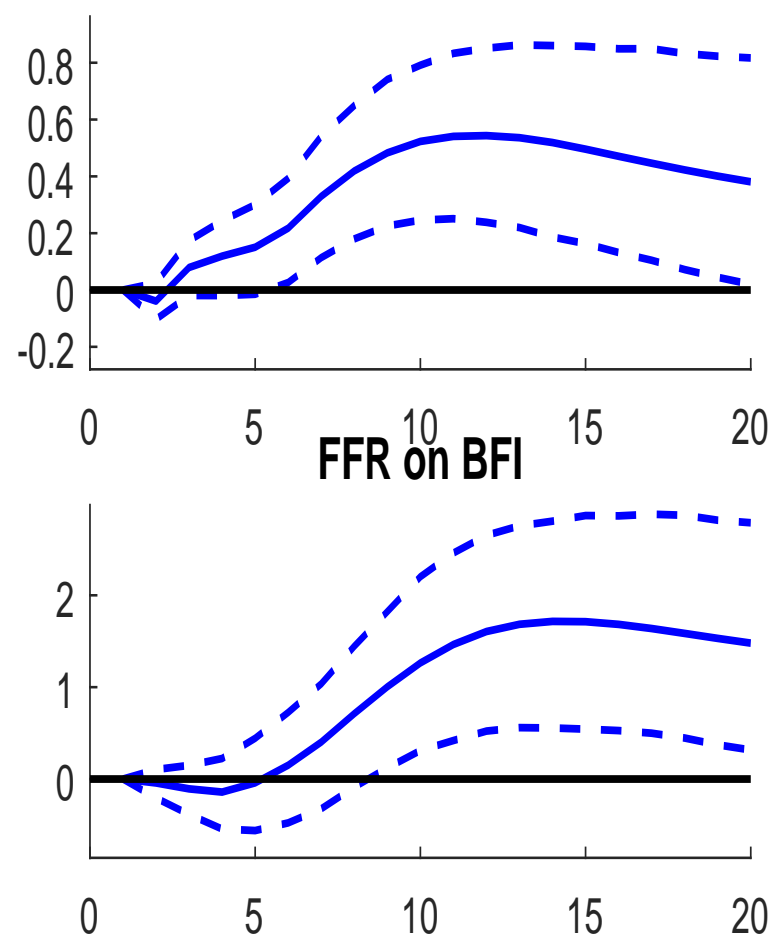

FFR on FC

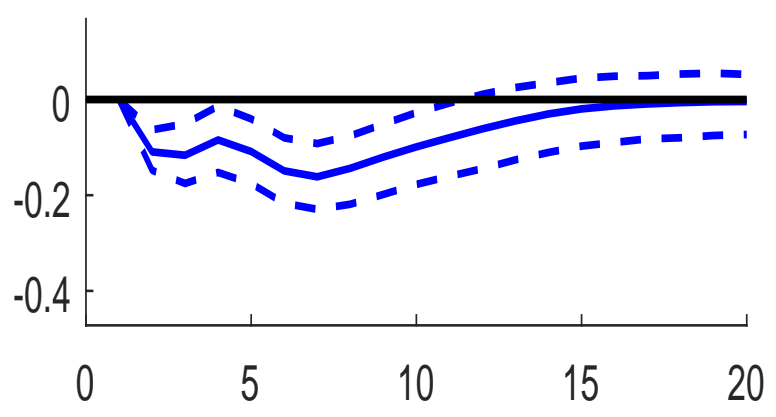

FFR on FFR

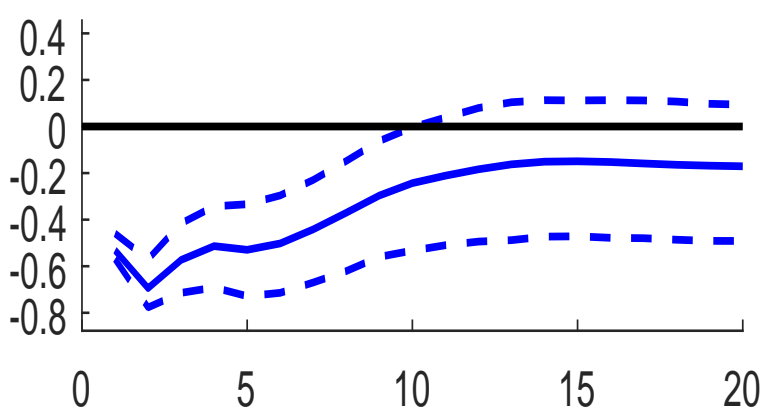

Figure 3: IRFs to NFCI and FFR Shocks IRFs and $90 \%$ confidence bands are from the baseline VAR model in which financial conditions are measured by the NFCI. The sample period is 1974Q2-2016Q1. 
FC on GDP
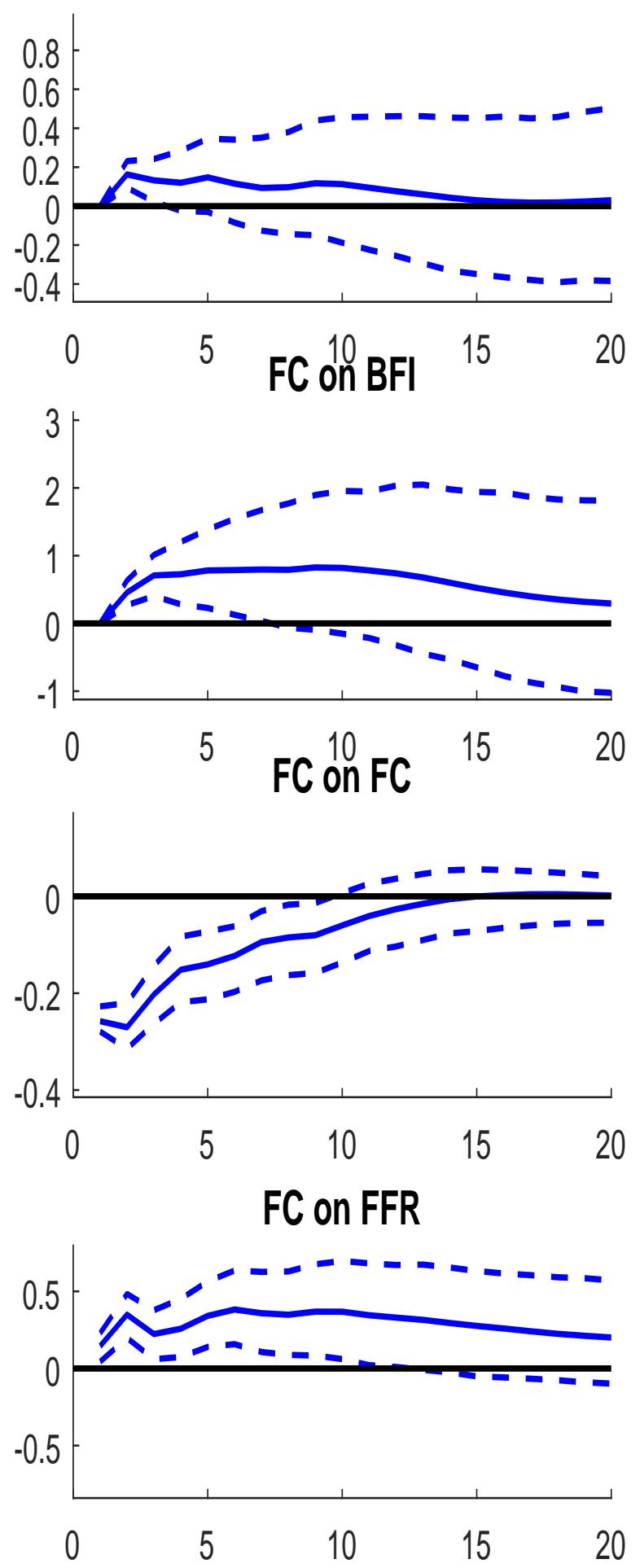

FFR on GDP


FFR on FC

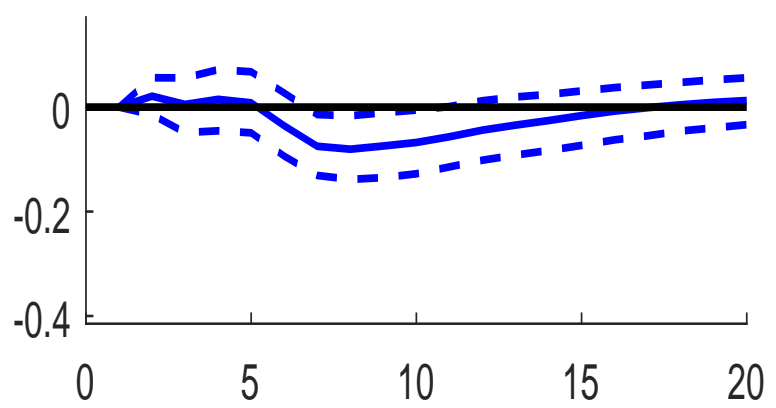

FFR on FFR

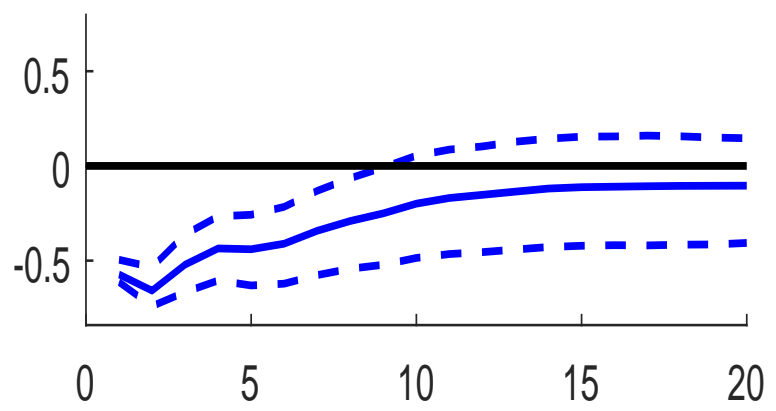

Figure 4: IRFs to Baa-Treasury Spread and FFR Shocks IRFs and $90 \%$ confidence bands are from the baseline VAR model in which financial conditions are measured by the Baa corporate bond spread over the 10-year Treasury. The sample period is 1974Q2-2016Q1. 
FC on GDP
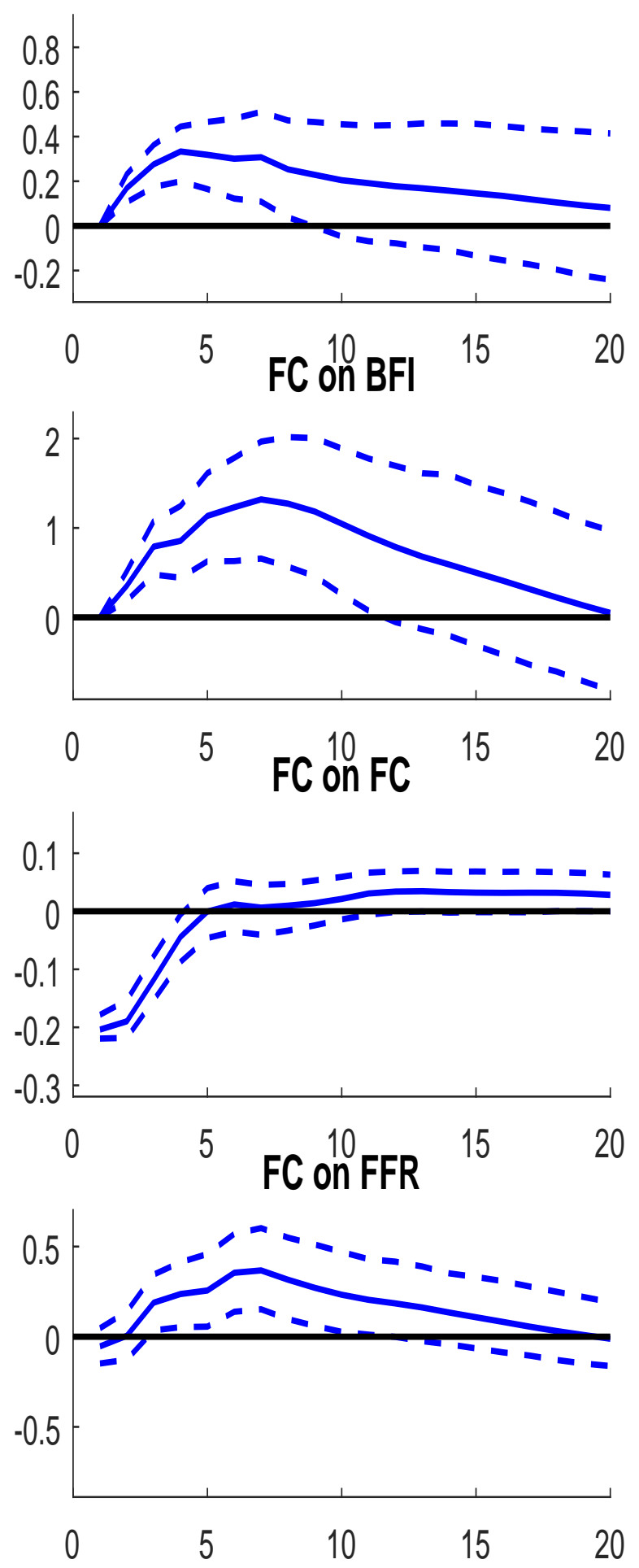

FFR on GDP
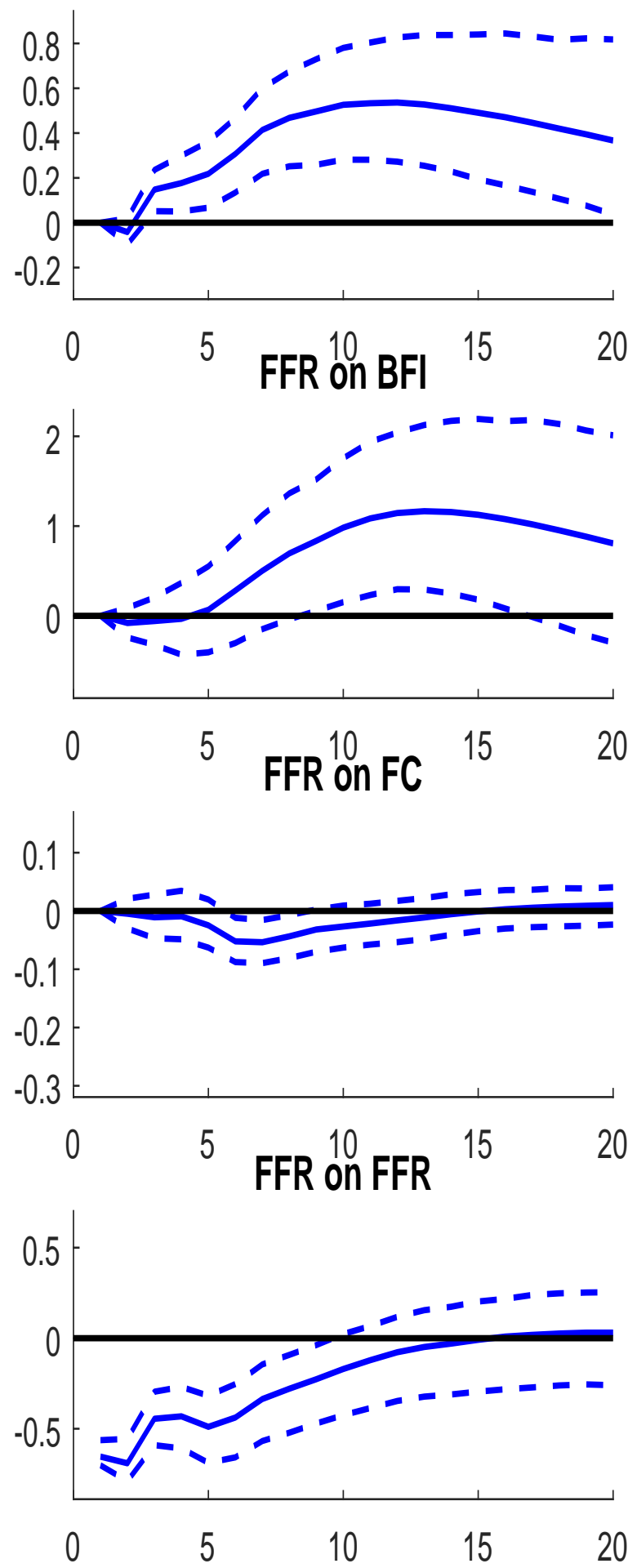

Figure 5: IRFs to FC and FFR Shocks: CEE Model IRFs and 90\% confidence bands are from the CEE VAR model in which financial conditions are measured by the excess bond premium. The sample period is 1974Q2-2016Q1. 
FC on GDP
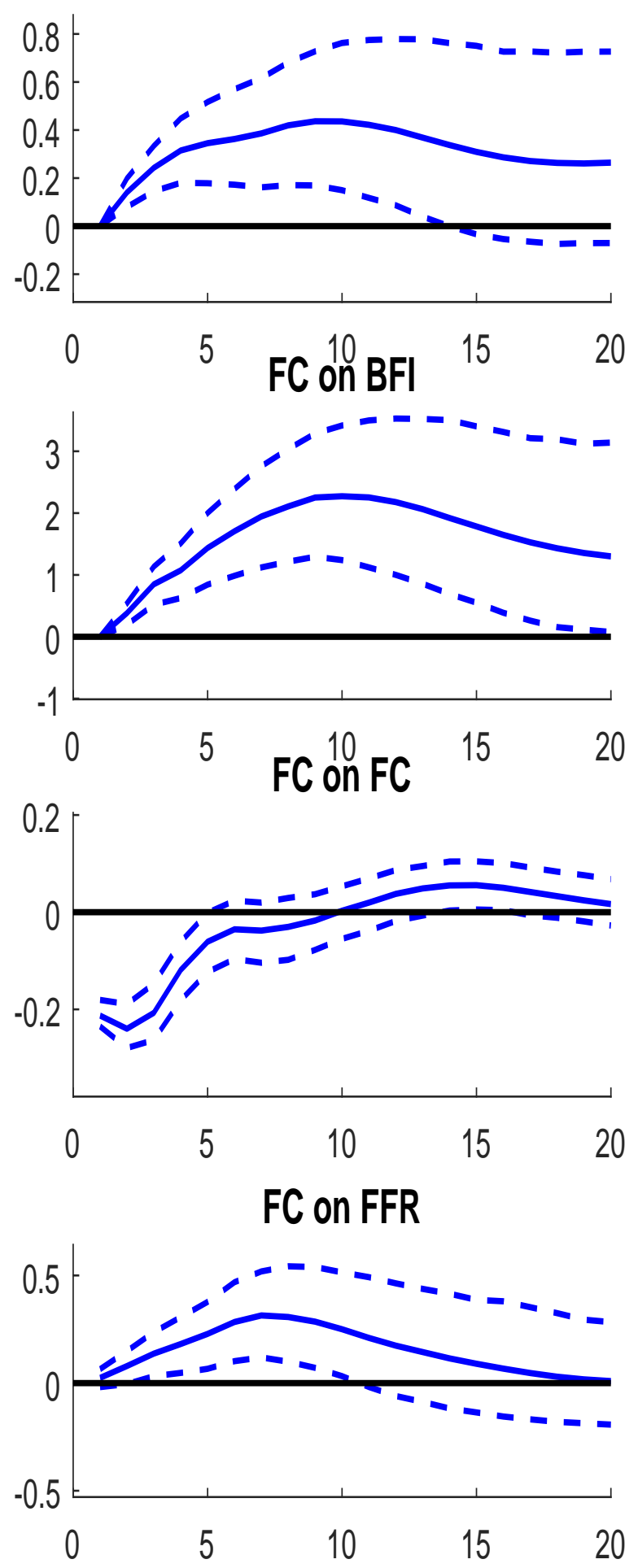

FFR on GDP
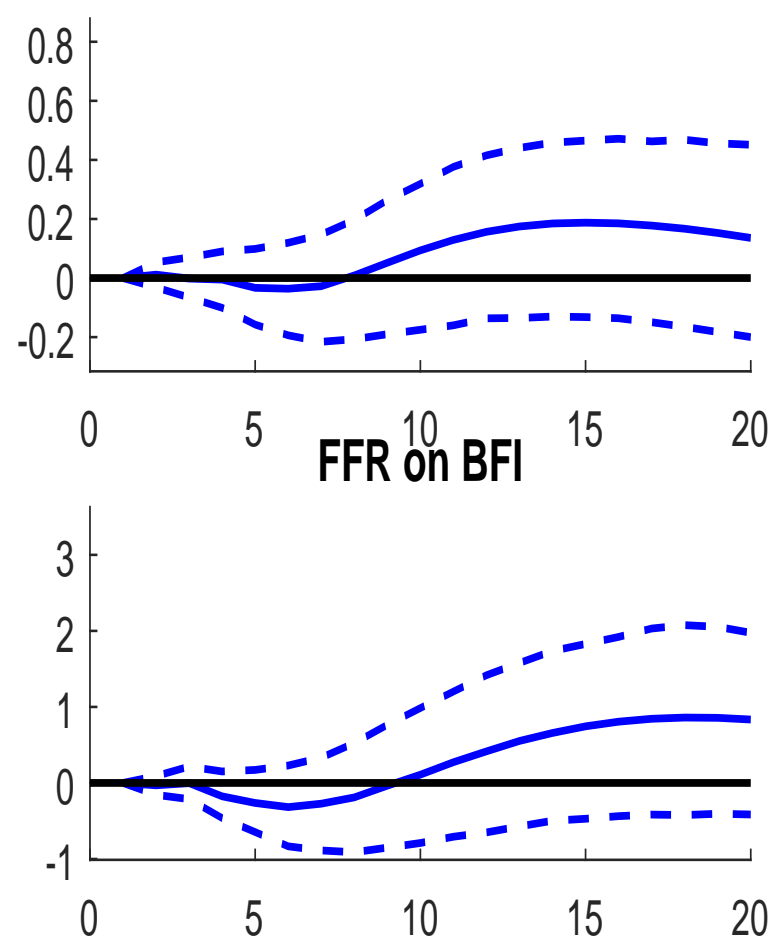

FFR on FC



FFR on FFR

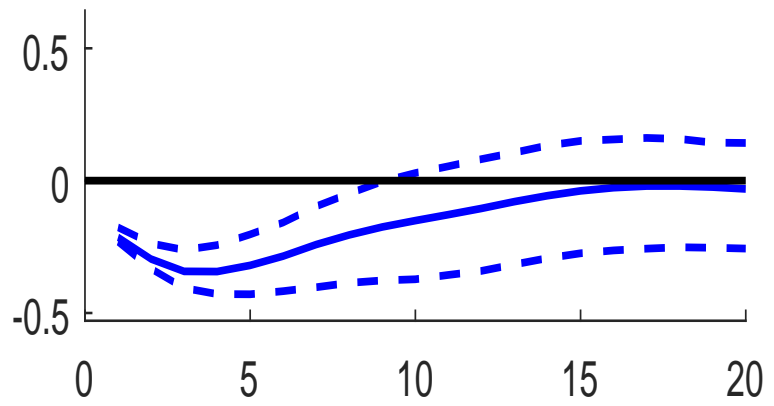

Figure 6: IRFs to FC and FFR Shocks: Post-1985 Sample IRFs and 90\% confidence bands are from the baseline VAR model in which financial conditions are measured by the excess bond premium. The sample period is 1985Q1-2016Q1. 

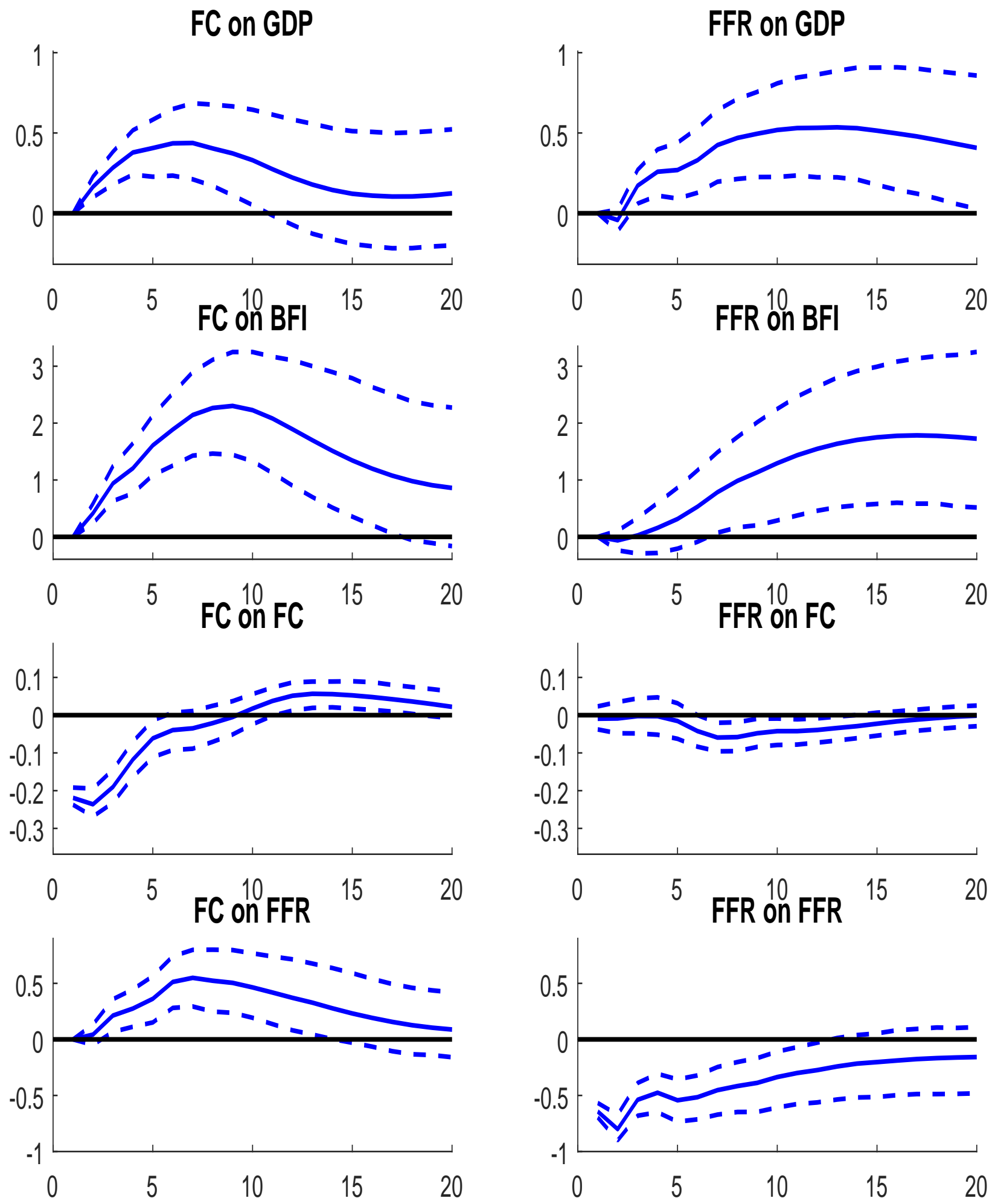

Figure 7: IRFs to FC and FFR Shocks: Alternative Identification Assumptions IRFs and $90 \%$ confidence bands are from a variation of the baseline VAR model in which FFR precedes the FC excess bond premium variable. The sample period is 1974Q2-2016Q1. 

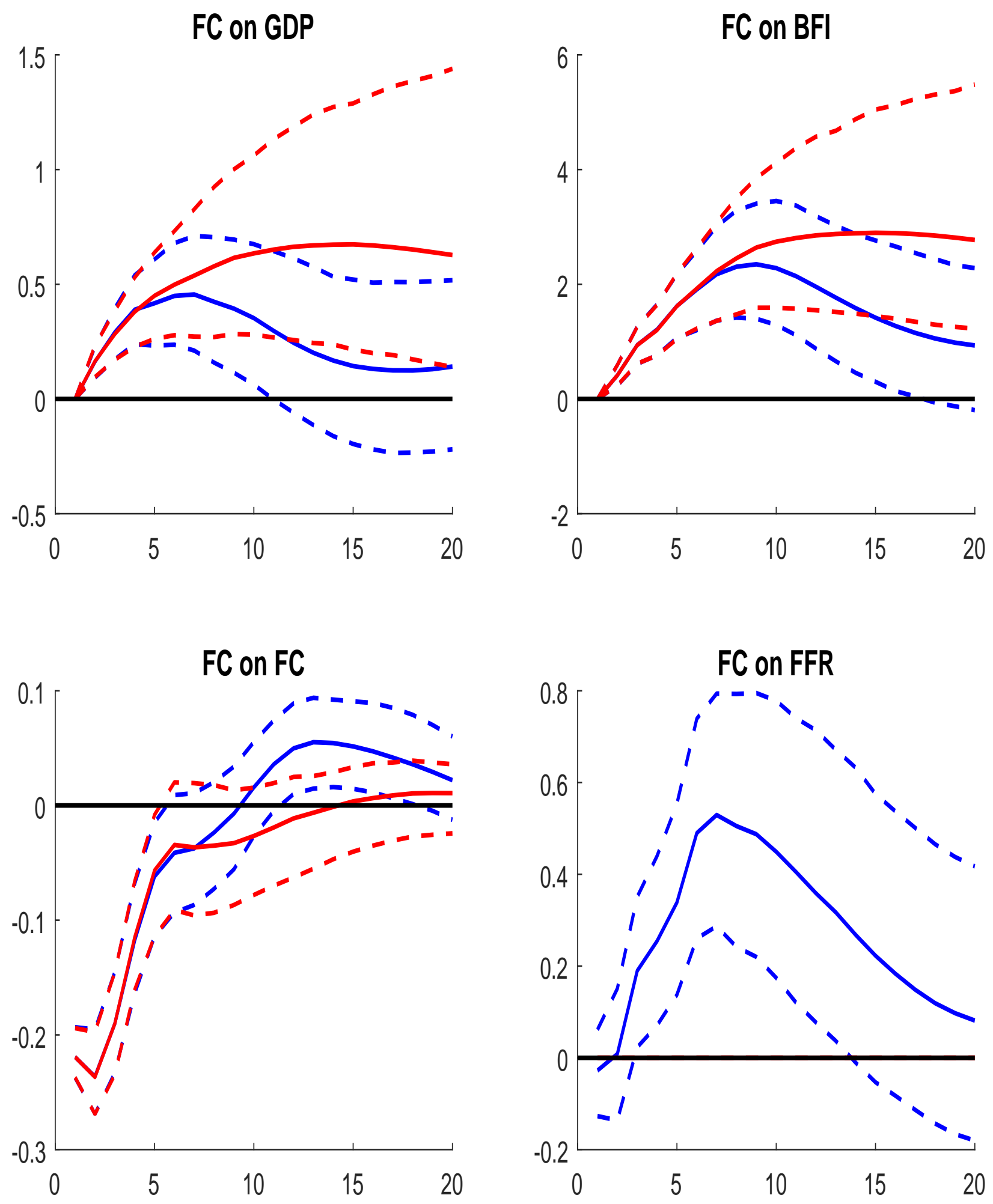

Figure 8: IRFs to a FC Shock with and without Monetary Policy Response The plots compare the response to an excess bond premium shock when monetary policy reacts to the shock (blue line) to the case in which monetary policy does not react to the shock (red line). IRFs and $90 \%$ confidence bands are from the baseline VAR model. The sample period is 1974Q2-2016Q1. 

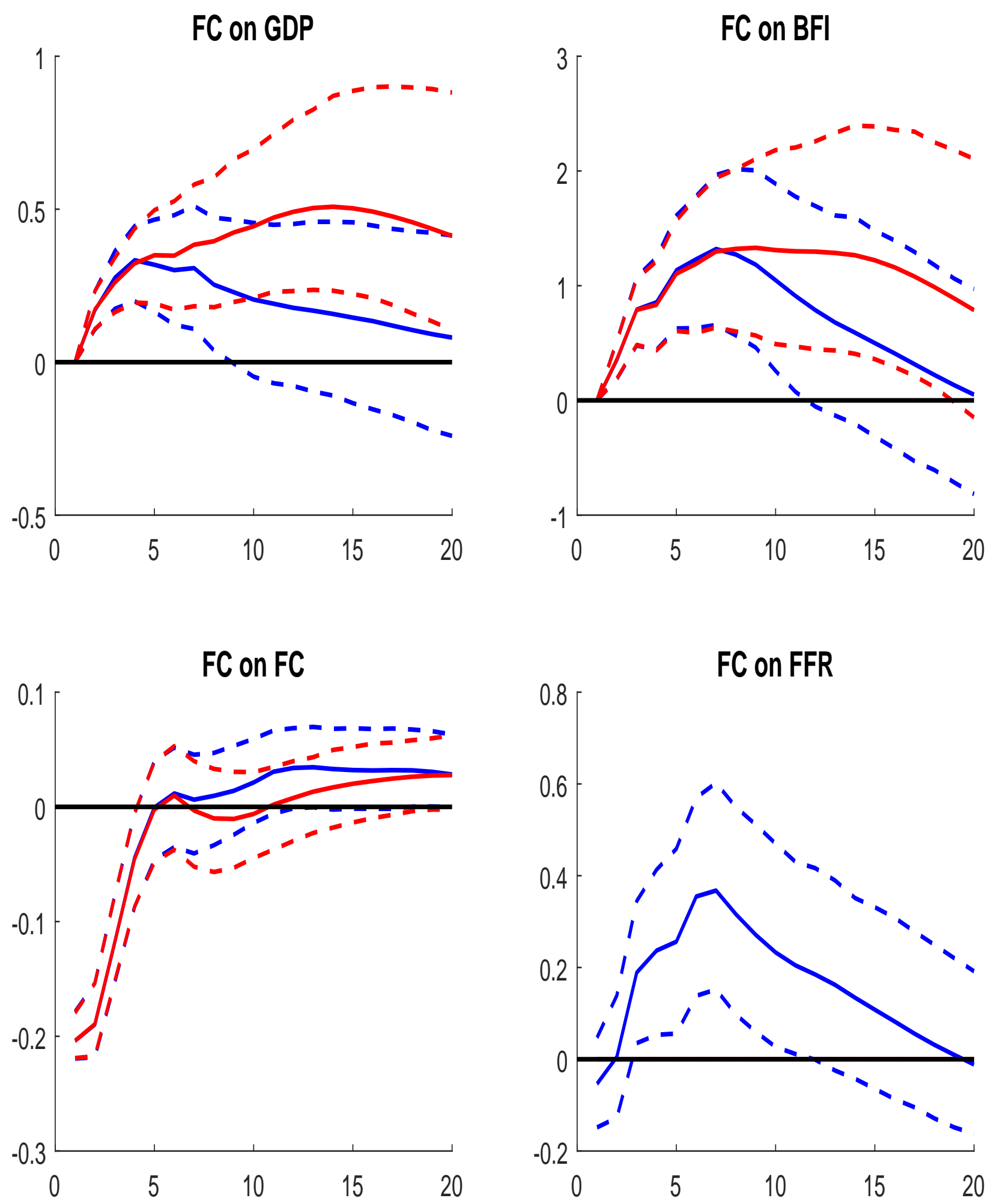

Figure 9: IRFs to a FC Shock with and without Monetary Policy Response: CEE Model The plots compare the response to an excess bond premium shock when monetary policy reacts to the shock (blue line) to the case in which monetary policy does not react to the shock (red line). IRFs and 90\% confidence bands are from the CEE VAR model. The sample period is 1974Q22016Q1. 

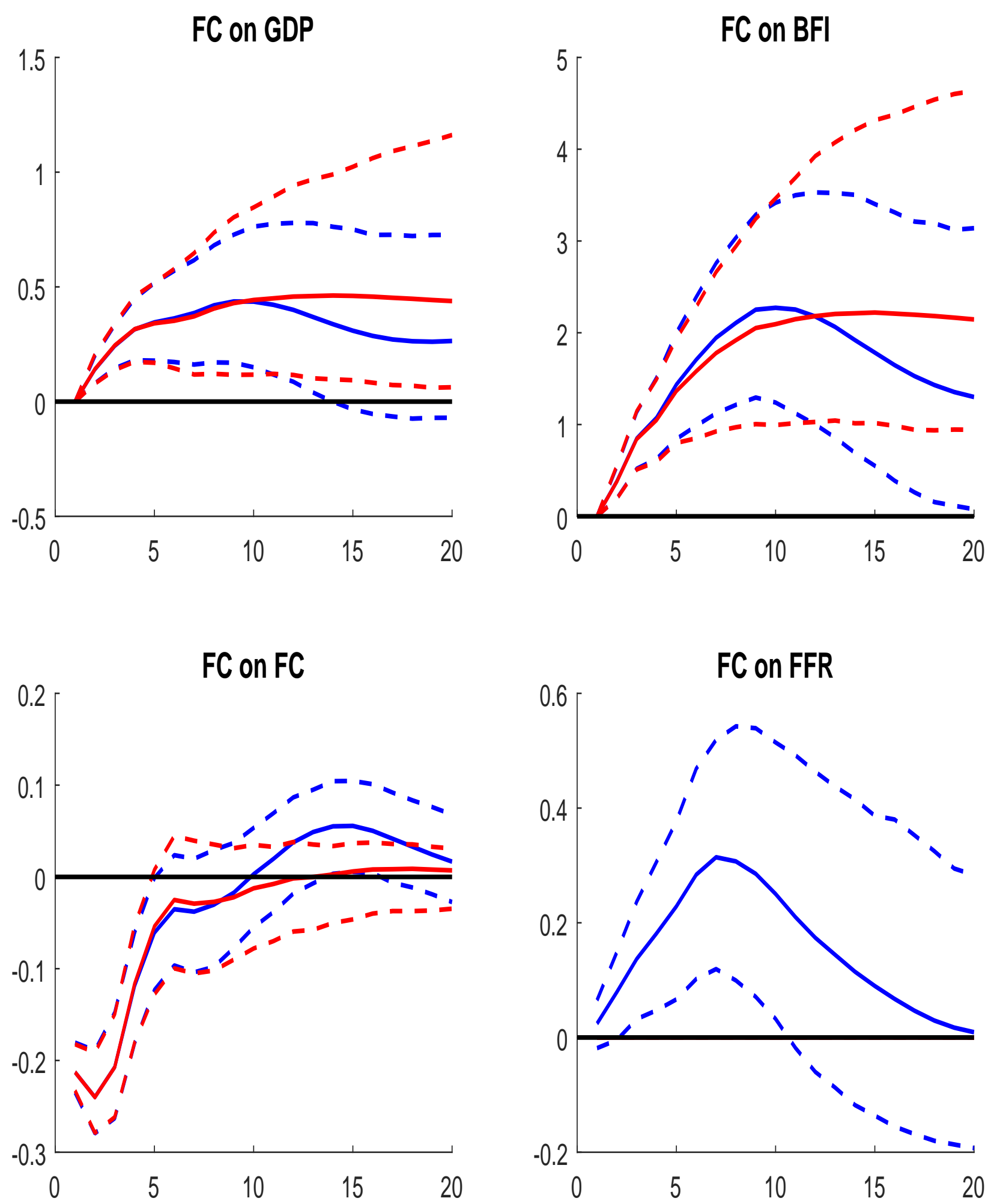

Figure 10: IRFs to a FC Shock with and without Monetary Policy Response: Post-1985 Sample The plots compare the response to an excess bond premium shock when monetary policy reacts to the shock (blue line) to the case in which monetary policy does not react to the shock (red line). IRFs and 90\% confidence bands are from the baseline VAR model. The sample period is 1985Q12016Q1. 

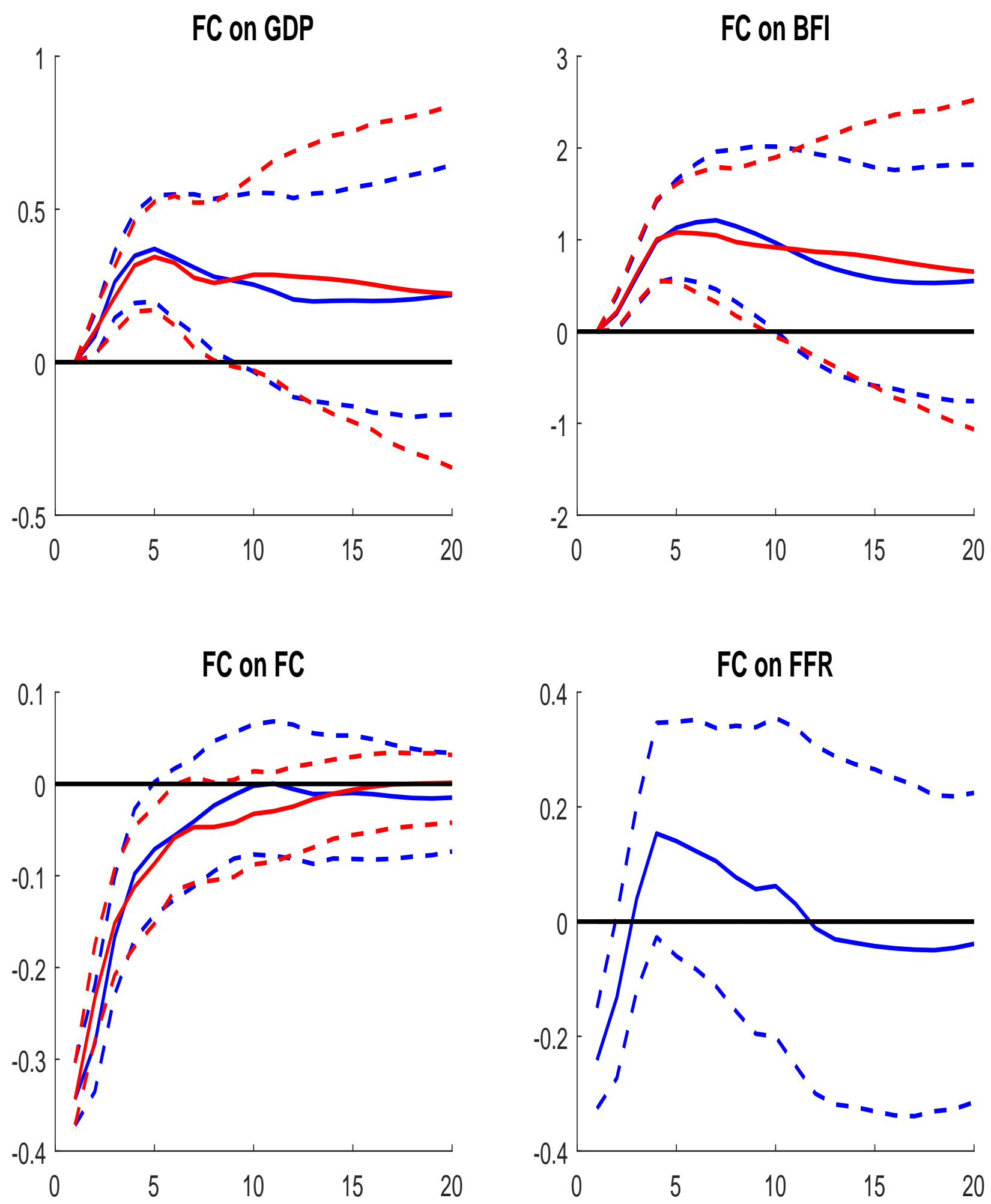

Figure 11: IRFs to a NFCI Shock with and without Monetary Policy

Response The plots compare the response to a NFCI shock when monetary policy reacts to the shock (blue line) to the case in which monetary policy does not react to the shock (red line). IRFs and $90 \%$ confidence bands are from the VAR model in which the NFCI is the proxy for financial conditions. The sample period is 1974Q2-2016Q1. 

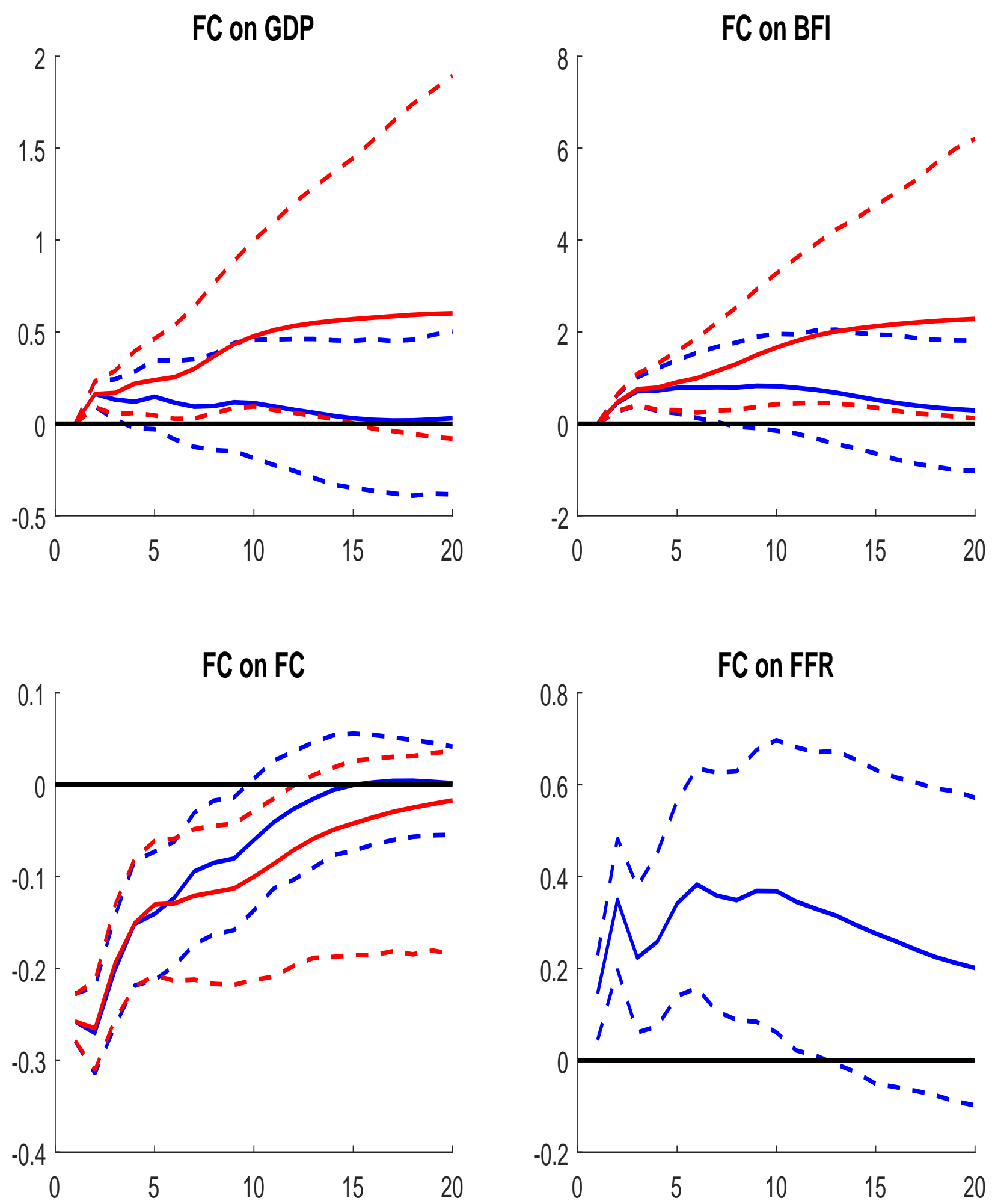

Figure 12: IRFs to a Baa-Treasury Spread Shock with and without

Monetary Policy Response The plots compare the response to a Baa-Treasury spread shock when monetary policy reacts to the shock (blue line) to the case in which monetary policy does not react to the shock (red line). IRFs and $90 \%$ confidence bands are from the VAR model in which the Baa-Treasury spread is the proxy for financial conditions. The sample period is 1974Q2-2016Q1. 


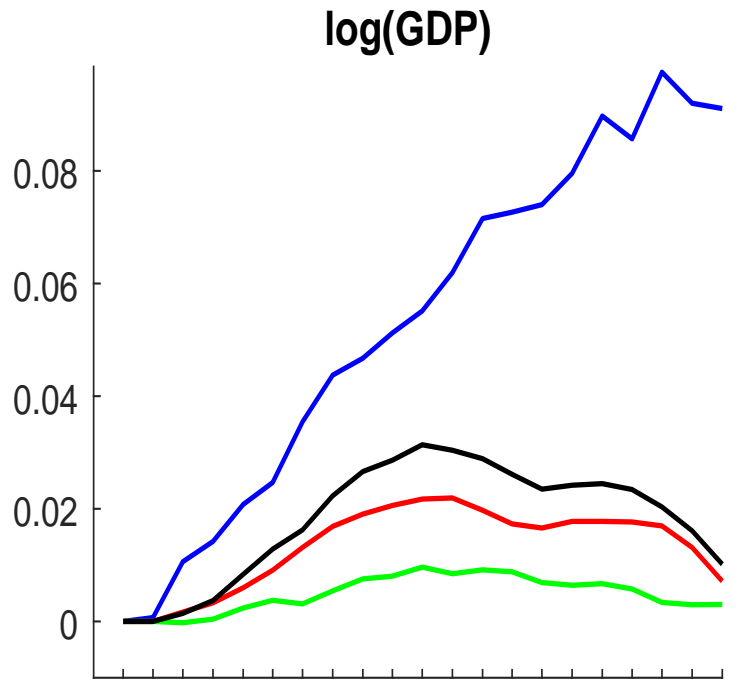

Q4-95 Q4-96 Q4-97 Q4-98 Q4-99 Q4-00

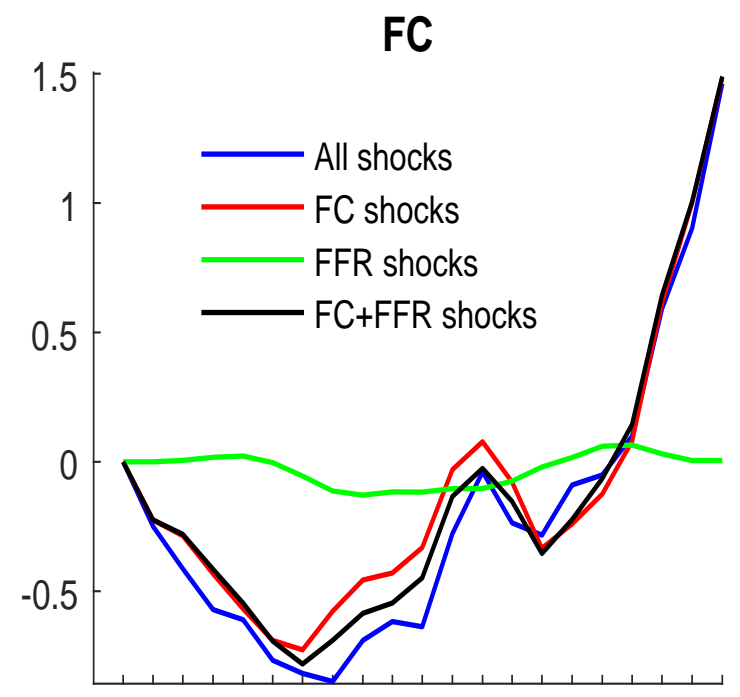

Q4-95 Q4-96 Q4-97 Q4-98 Q4-99 Q4-00

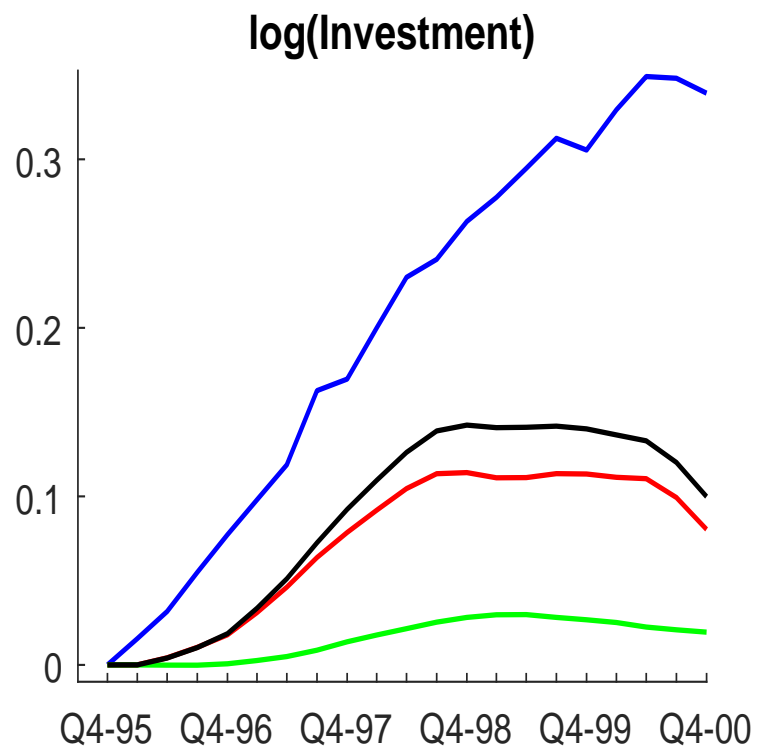

FFR

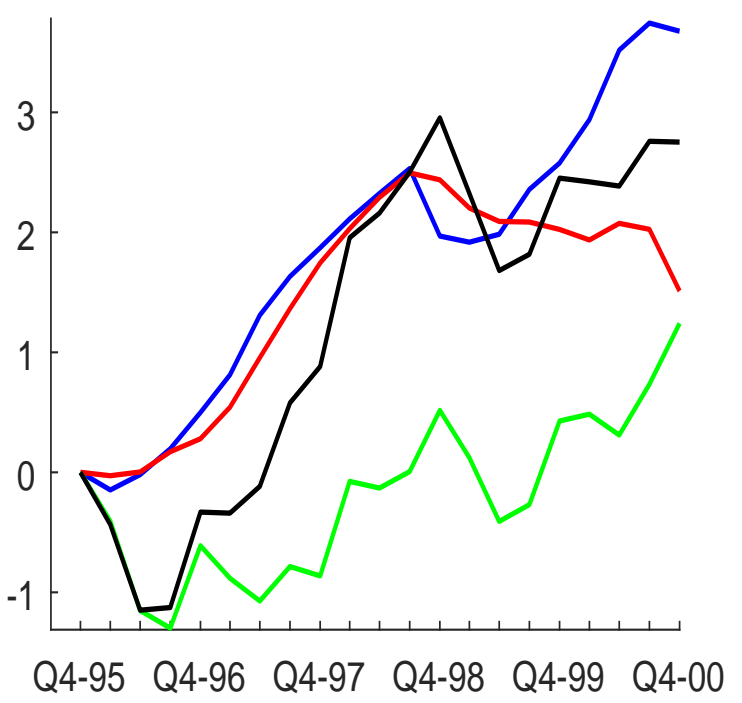

Figure 13: The Contribution of FC and FFR Shocks: 1996Q1-2000Q4

The blue line shows the total shocks to log-GDP, log-investment, financial conditions, and the federal funds rate over the 1996Q1-2000Q4 period identified using the baseline VAR model. The red and green lines show the contributions of financial conditions and federal funds rate shocks to the total shocks. The black line shows the combined effect of financial conditions and federal funds rate shocks. The estimation period for the baseline VAR is 1974Q2-2016Q1. 




FC

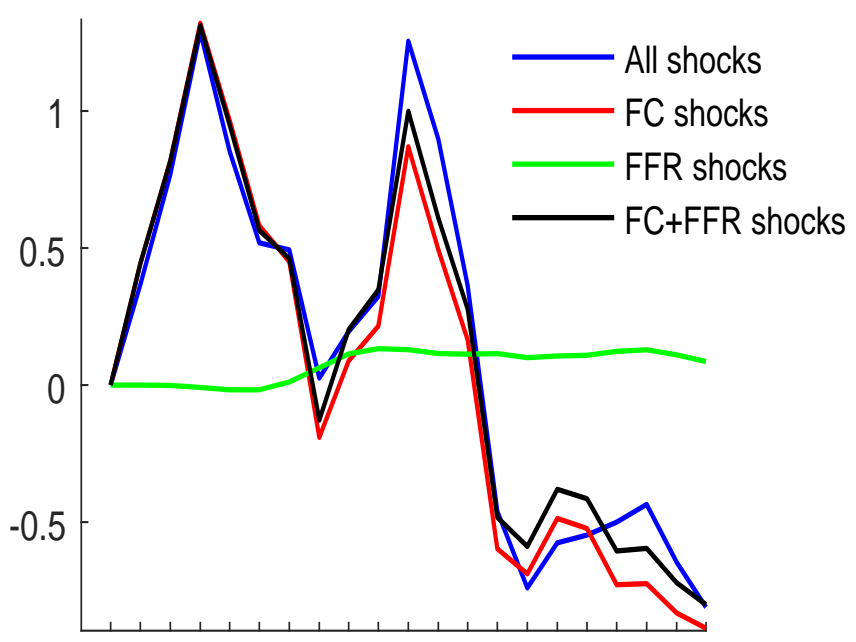

Q1-00 Q1-01 Q1-02 Q1-03 Q1-04 Q1-05

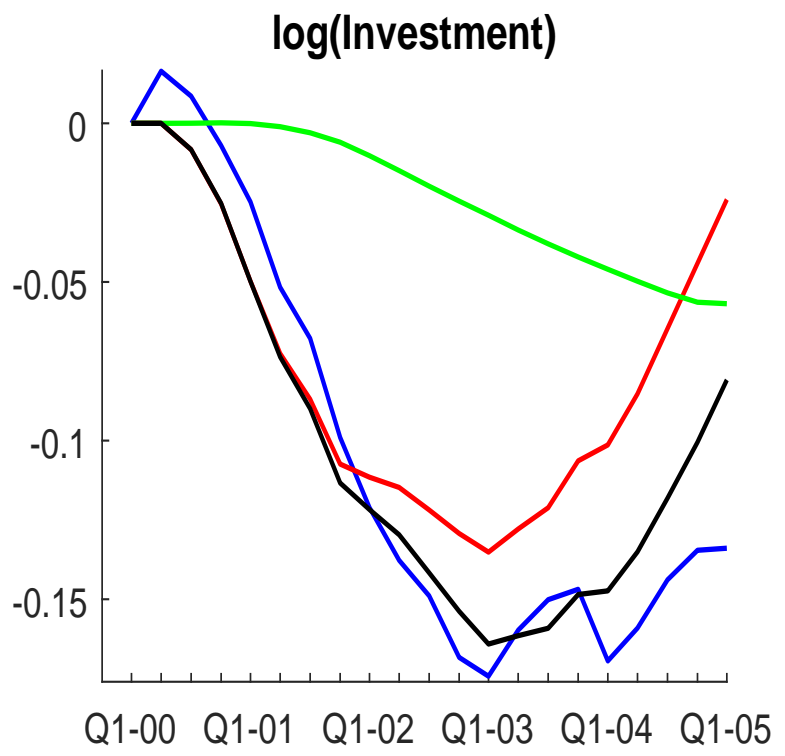

FFR

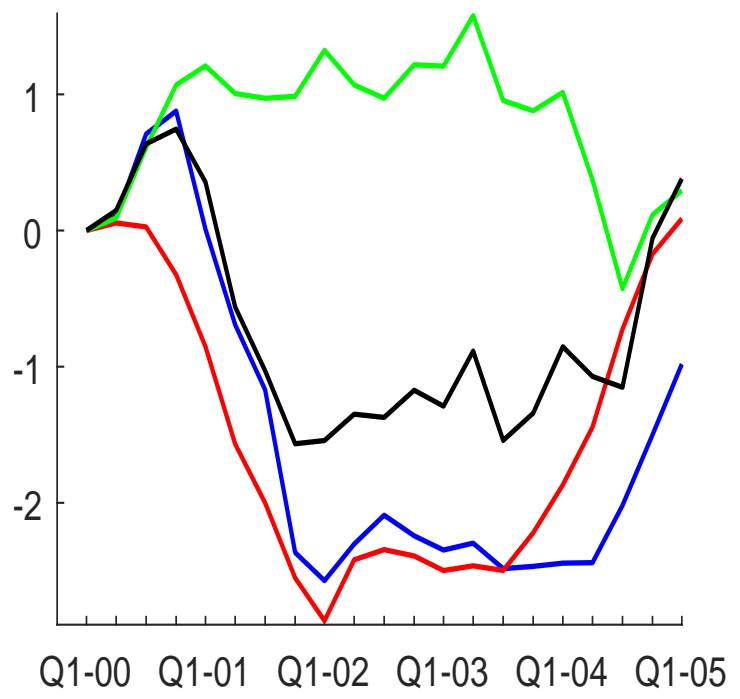

Figure 14: The Contribution of FC and FFR Shocks: 2000Q2-2005Q1

The blue line shows the total shocks to log-GDP, log-investment, financial conditions, and the federal funds rate over the 2000Q2-2005Q1 period identified using the baseline VAR model. The red and green lines show the contributions of financial conditions and federal funds rate shocks to the total shocks. The black line shows the combined effect of financial conditions and federal funds rate shocks. The estimation period for the baseline VAR is 1974Q2-2016Q1. 


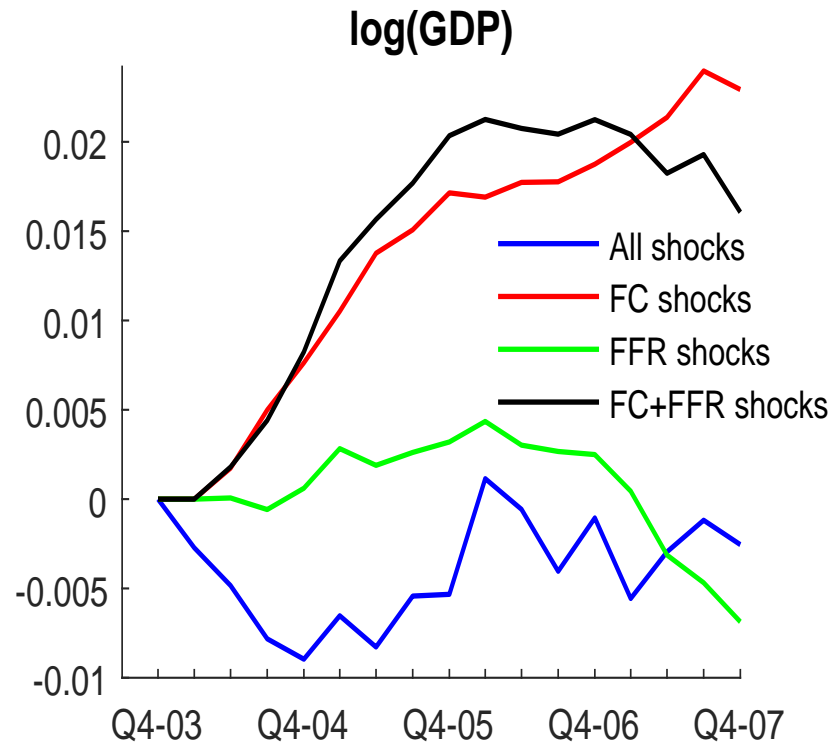

FC

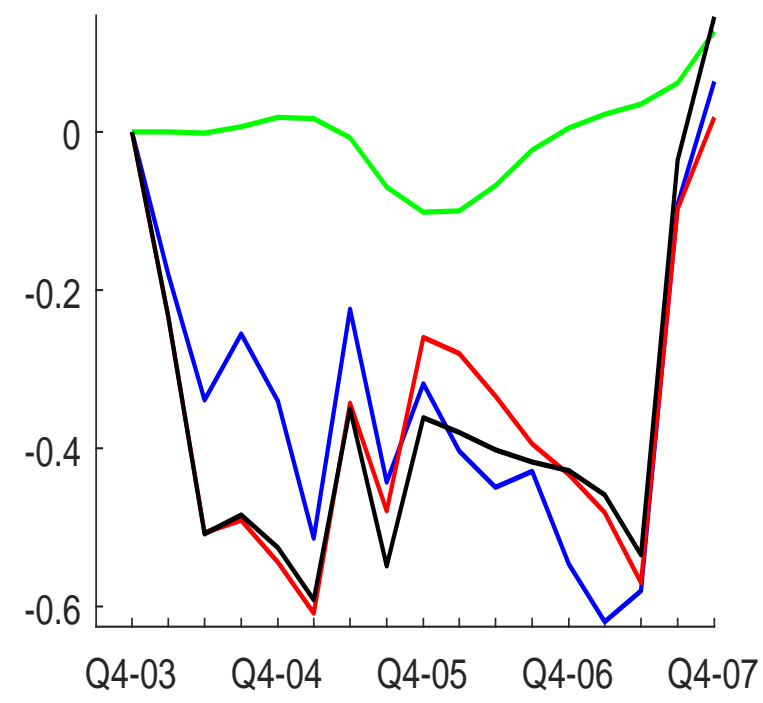

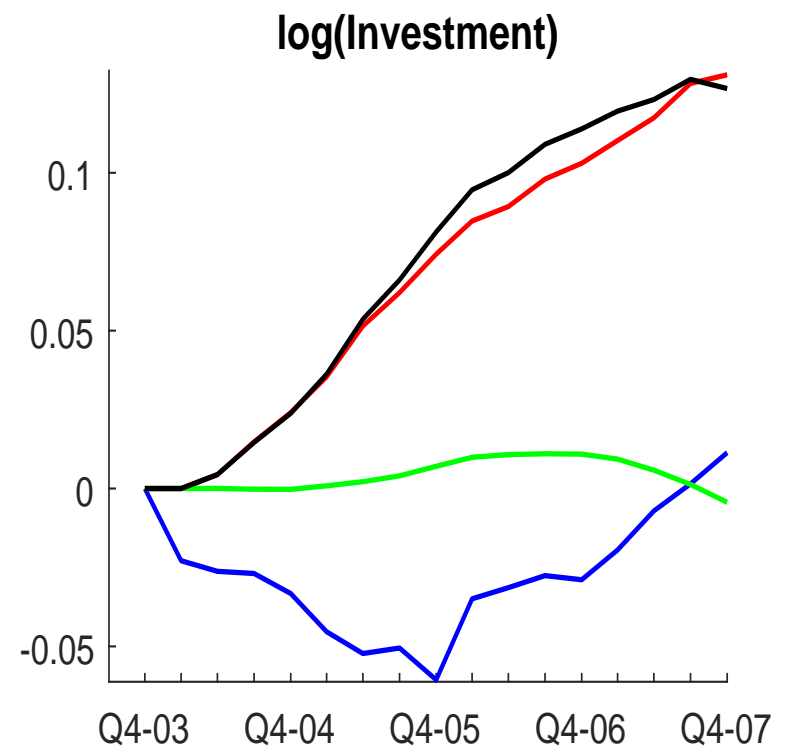

FFR

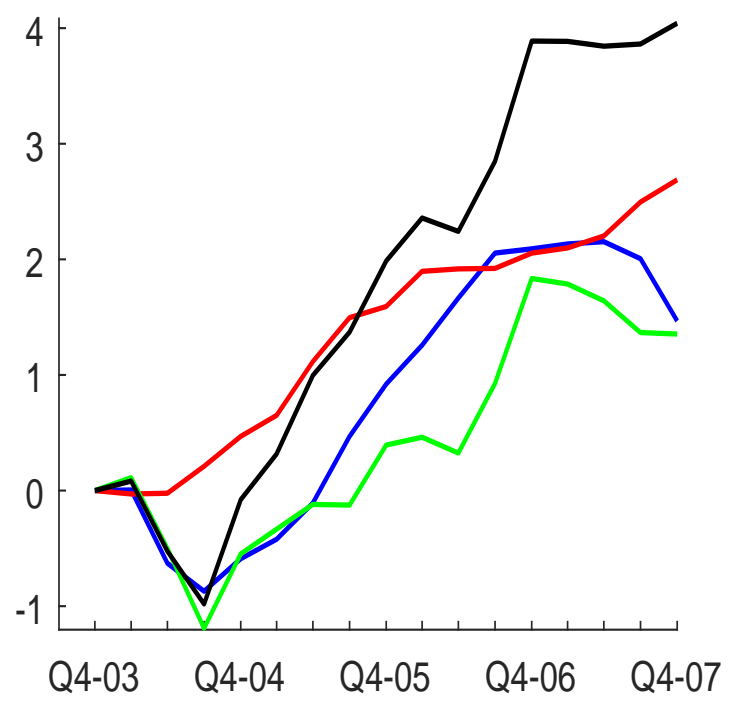

Figure 15: The Contribution of FC and FFR Shocks: 2004Q1-2007Q4

The blue line shows the total shocks to log-GDP, log-investment, financial conditions, and the federal funds rate over the 2004Q1-2007Q4 period identified using the baseline VAR model. The red and green lines show the contributions of financial conditions and federal funds rate shocks to the total shocks. The black line shows the combined effect of financial conditions and federal funds rate shocks. The estimation period for the baseline VAR is 1974Q2-2016Q1. 

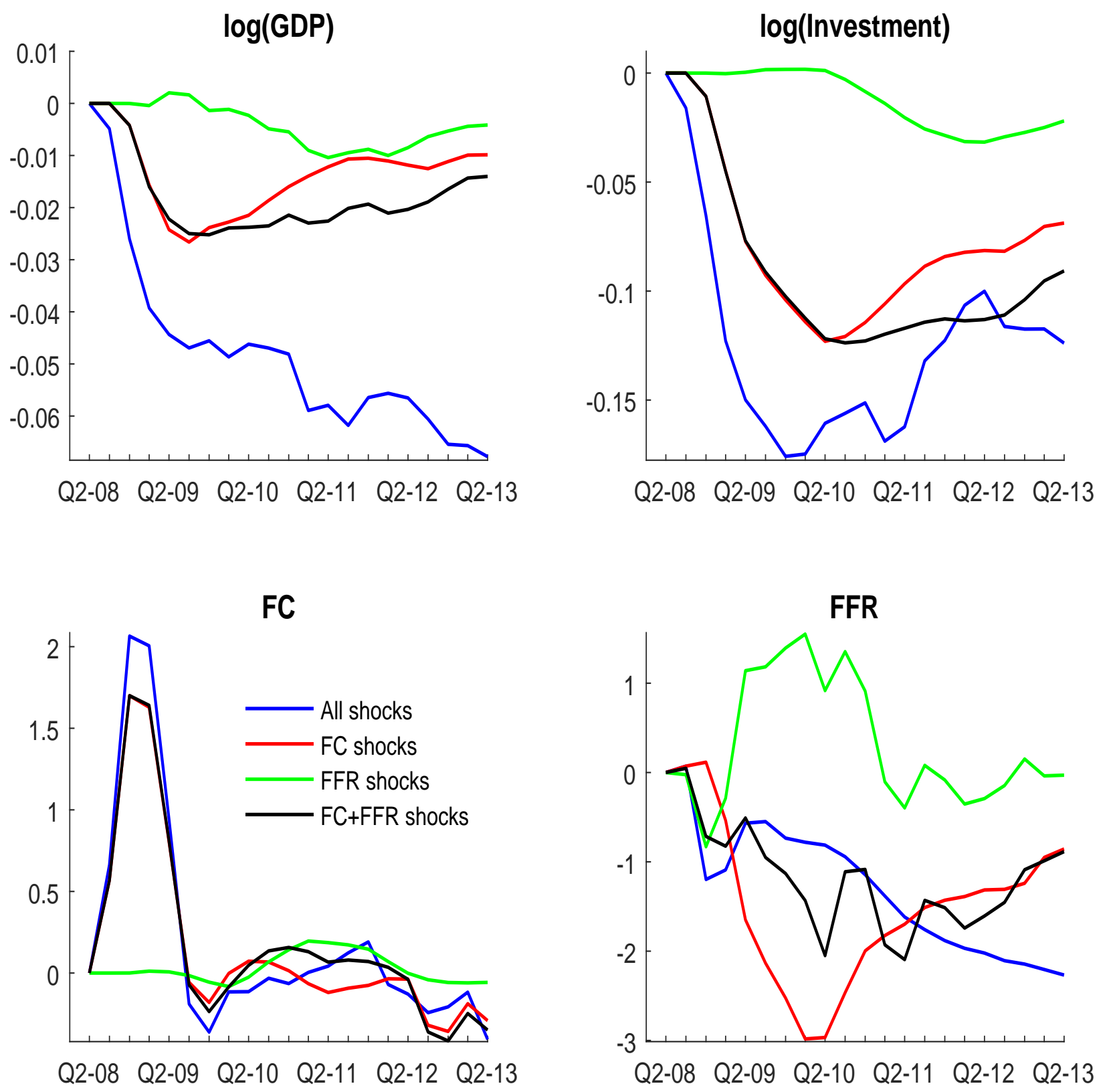

Figure 16: The Contribution of FC and FFR Shocks: 2008Q3-2013Q2

The blue line shows the total shocks to log-GDP, log-investment, financial conditions, and the federal funds rate over the 2008Q3-2013Q2 period identified using the baseline VAR model. The red and green lines show the contributions of financial conditions and federal funds rate shocks to the total shocks. The black line shows the combined effect of financial conditions and federal funds rate shocks. The estimation period for the baseline VAR is 1974Q2-2016Q1. 
Horizon

\begin{tabular}{|c|c|c|c|c|c|}
\hline \multirow{2}{*}{ Shocks } & \\
\hline & 4 & 8 & 12 & 20 & $\infty$ \\
\hline \multicolumn{6}{|c|}{ Panel A: GDP } \\
\hline $\mathrm{FC}$ & 10.92 & 10.31 & 11.53 & 12.02 & 12.22 \\
\hline FFR & 4.99 & 8.15 & 8.55 & 8.89 & 8.94 \\
\hline Other & 84.09 & 81.54 & 79.92 & 79.08 & 78.84 \\
\hline \multicolumn{6}{|c|}{ Panel B: BFI } \\
\hline $\mathrm{FC}$ & 17.06 & 22.32 & 22.50 & 24.88 & 24.96 \\
\hline FFR & 0.23 & 4.32 & 7.20 & 7.34 & 7.54 \\
\hline Other & 82.70 & 73.36 & 70.30 & 67.78 & 67.50 \\
\hline \multicolumn{6}{|c|}{ Panel C: FC } \\
\hline $\mathrm{FC}$ & 87.86 & 80.76 & 76.04 & 74.83 & 73.78 \\
\hline FFR & 0.16 & 6.36 & 10.18 & 10.13 & 10.18 \\
\hline Other & 11.98 & 12.88 & 13.77 & 15.04 & 16.04 \\
\hline \multicolumn{6}{|c|}{ Panel D: FFR } \\
\hline $\mathrm{FC}$ & 3.71 & 16.76 & 20.64 & 18.01 & 13.00 \\
\hline FFR & 43.27 & 31.60 & 25.49 & 20.08 & 15.35 \\
\hline Other & 53.02 & 51.63 & 53.87 & 61.91 & 71.65 \\
\hline
\end{tabular}

Table 1: Variance Decomposition Results For each of the GDP, BFI, FC, and FFR variables, we decompose the variance of the forecasting error into its components due to FC, FFR, and other shocks. The first four columns show the decomposition for the forecast error at horizons from one to five years, while the last column has the unconditional variance decomposition. The results are from the baseline VAR model in which financial conditions are measured by the excess bond premium. The sample period is 1974Q2-2016Q1. 
Horizon

\begin{tabular}{|c|c|c|c|c|c|}
\hline \multirow{2}{*}{ Shocks } & \\
\hline & 4 & 8 & 12 & 20 & $\infty$ \\
\hline \multicolumn{6}{|c|}{ Panel A: GDP } \\
\hline $\mathrm{FC}$ & 14.52 & 14.39 & 10.73 & 7.04 & 5.54 \\
\hline FFR & 3.69 & 14.92 & 24.77 & 27.38 & 12.41 \\
\hline Other & 81.79 & 70.68 & 64.50 & 65.58 & 82.05 \\
\hline \multicolumn{6}{|c|}{ Panel B: BFI } \\
\hline $\mathrm{FC}$ & 9.61 & 17.97 & 17.50 & 13.08 & 9.87 \\
\hline FFR & 0.07 & 1.95 & 7.52 & 13.57 & 10.88 \\
\hline Other & 90.32 & 80.08 & 74.98 & 73.35 & 79.24 \\
\hline \multicolumn{6}{|c|}{ Panel C: FC } \\
\hline $\mathrm{FC}$ & 71.57 & 56.59 & 50.07 & 46.19 & 43.15 \\
\hline FFR & 0.17 & 5.02 & 5.59 & 4.95 & 5.24 \\
\hline Other & 28.26 & 38.39 & 44.34 & 48.87 & 51.61 \\
\hline \multicolumn{6}{|c|}{ Panel D: FFR } \\
\hline $\mathrm{FC}$ & 3.74 & 11.48 & 13.34 & 13.50 & 13.22 \\
\hline FFR & 50.94 & 42.10 & 37.03 & 34.40 & 30.98 \\
\hline Other & 45.32 & 46.42 & 49.64 & 52.10 & 55.80 \\
\hline
\end{tabular}

Table 2: Variance Decomposition Results: CEE Model For each of the GDP, BFI, FC, and FFR variables, we decompose the variance of the forecasting error into its components due to FC, FFR, and other shocks. The first four columns show the decomposition for the forecast error at horizons from one to five years, while the last column has the unconditional variance decomposition. The results are from the CEE VAR model in which financial conditions are measured by the excess bond premium. The sample period is 1974Q2-2016Q1. 


\section{The Interplay Between Financial Conditions and Monetary Policy Shocks Online Appendix}

Marco Bassetto, Luca Benzoni, and Trevor Serrao 

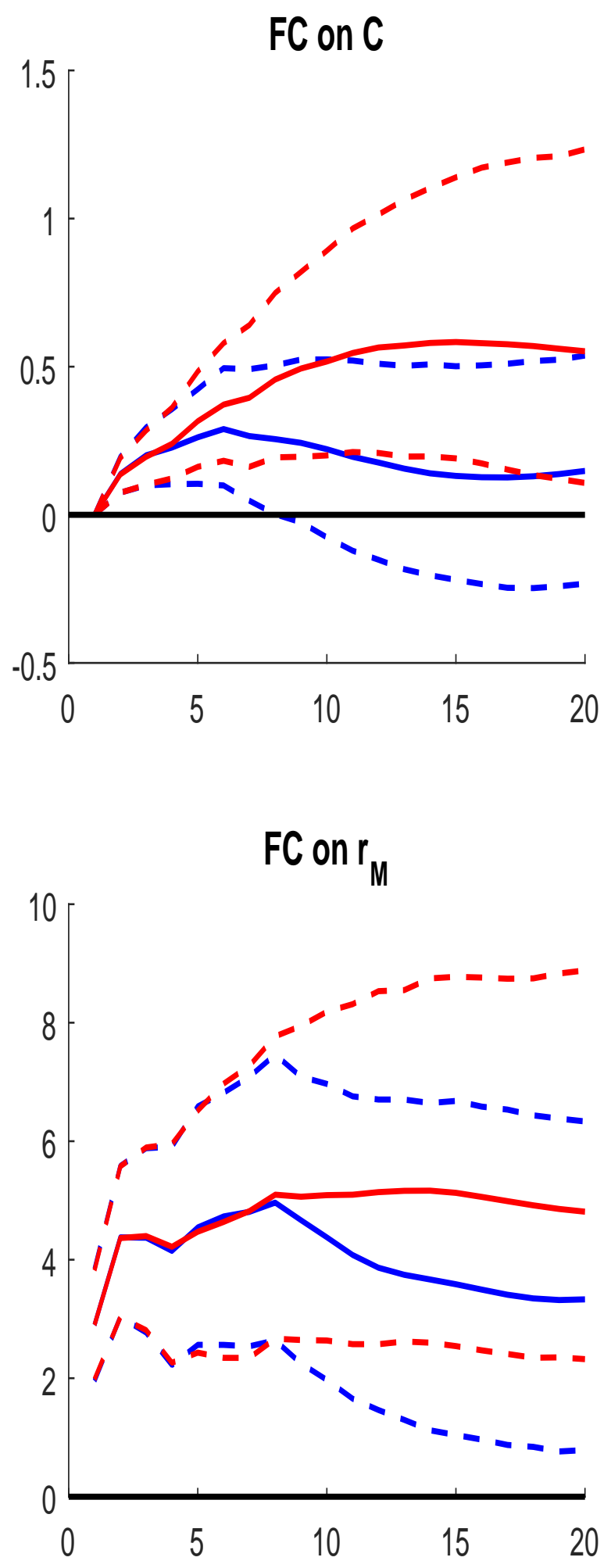

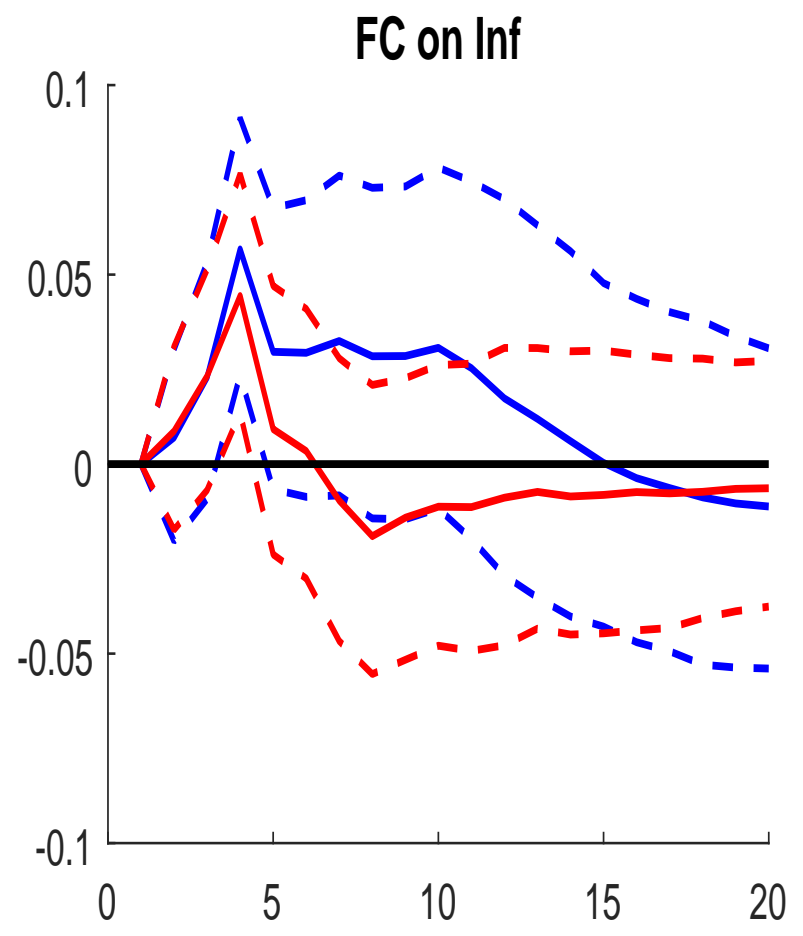

FC on CMT10

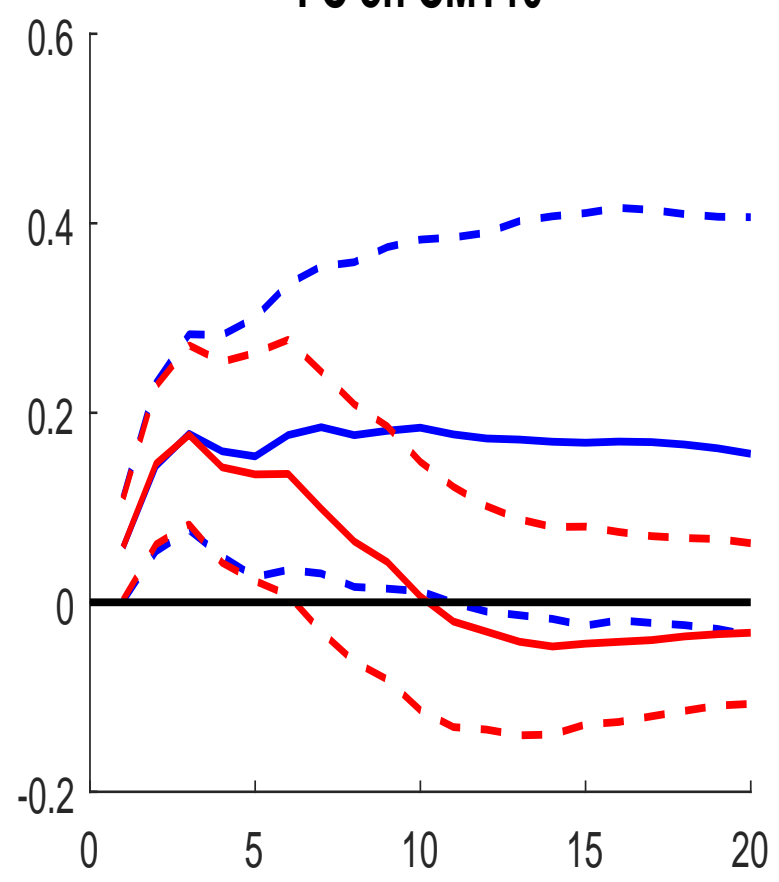

Figure 17: IRFs to a FC Shock with and without Monetary Policy Response The plots compare the response to an excess bond premium shock when monetary policy reacts to the shock (blue line) to the case in which monetary policy does not react to the shock (red line). IRFs and $90 \%$ confidence bands are from the baseline VAR model. The sample period is 1974Q2-2016Q1. 

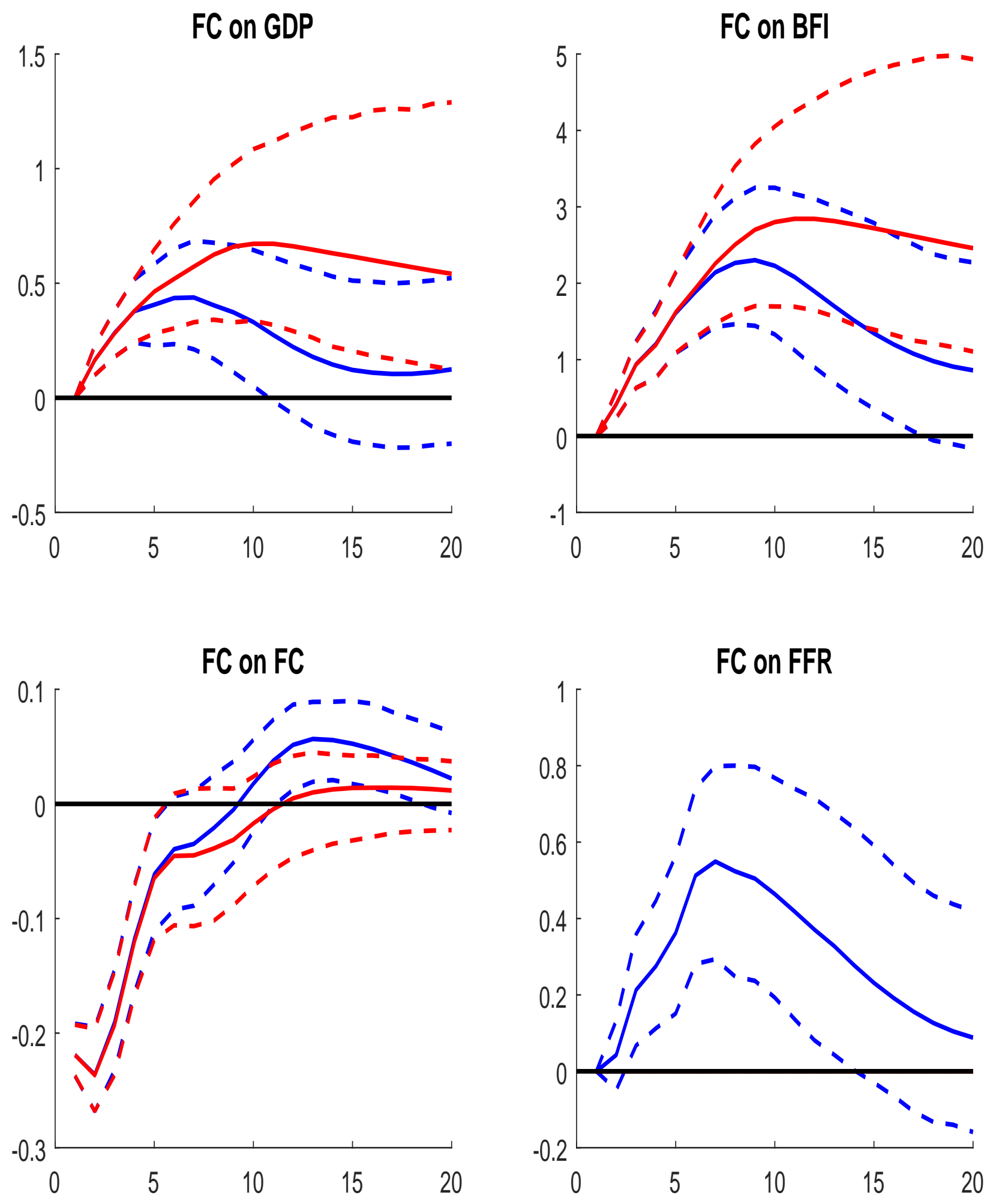

Figure 18: IRFs to a FC Shock with and without Monetary Policy Response: Alternative Identification Assumptions The plots compare the response to an excess bond premium shock when monetary policy reacts to the shock (blue line) to the case in which monetary policy does not react to the shock (red line). IRFs and 90\% confidence bands are from a variation of the baseline VAR model in which FFR precedes the FC excess bond premium variable. The sample period is 1974Q2-2016Q1. 
Horizon

\begin{tabular}{|c|c|c|c|c|c|}
\hline \multirow{2}{*}{ Shocks } & \\
\hline & 4 & 8 & 12 & 20 & $\infty$ \\
\hline \multicolumn{6}{|c|}{ Panel A: GDP } \\
\hline $\mathrm{FC}$ & 9.77 & 9.08 & 9.11 & 9.02 & 8.77 \\
\hline FFR & 3.63 & 7.93 & 8.79 & 9.30 & 9.28 \\
\hline Other & 86.60 & 82.99 & 82.10 & 81.68 & 81.95 \\
\hline \multicolumn{6}{|c|}{ Panel B: BFI } \\
\hline $\mathrm{FC}$ & 11.01 & 9.82 & 9.90 & 10.01 & 10.00 \\
\hline FFR & 0.23 & 5.55 & 10.14 & 10.39 & 10.46 \\
\hline Other & 88.76 & 84.63 & 79.96 & 79.60 & 79.54 \\
\hline \multicolumn{6}{|c|}{ Panel C: FC } \\
\hline $\mathrm{FC}$ & 56.73 & 39.97 & 34.08 & 31.69 & 30.65 \\
\hline FFR & 7.87 & 18.44 & 20.47 & 19.39 & 18.80 \\
\hline Other & 35.39 & 41.59 & 45.45 & 48.92 & 50.55 \\
\hline \multicolumn{6}{|c|}{ Panel D: FFR } \\
\hline $\mathrm{FC}$ & 3.56 & 2.54 & 1.98 & 1.60 & 1.22 \\
\hline FFR & 47.82 & 36.97 & 30.10 & 24.19 & 18.52 \\
\hline Other & 48.62 & 60.49 & 67.92 & 74.21 & 80.26 \\
\hline
\end{tabular}

Table 3: Variance Decomposition Results: NFCI For each of the GDP, BFI, $\mathrm{FC}$, and FFR variables, we decompose the variance of the forecasting error into its components due to FC, FFR, and other shocks. The first four columns show the decomposition for the forecast error at horizons from one to five years, while the last column has the unconditional variance decomposition. The results are from the baseline VAR model in which financial conditions are measured by the NFCI. The sample period is 1974Q2-2016Q1. 
Horizon

\begin{tabular}{|c|c|c|c|c|c|}
\hline \multirow{2}{*}{ Shocks } & \\
\hline & 4 & 8 & 12 & 20 & $\infty$ \\
\hline \multicolumn{6}{|c|}{ Panel A: GDP } \\
\hline $\mathrm{FC}$ & 5.72 & 5.49 & 5.58 & 5.66 & 5.86 \\
\hline FFR & 5.35 & 8.98 & 9.36 & 9.72 & 9.64 \\
\hline Other & 88.93 & 85.53 & 85.06 & 84.62 & 84.50 \\
\hline \multicolumn{6}{|c|}{ Panel B: BFI } \\
\hline $\mathrm{FC}$ & 8.54 & 7.02 & 6.71 & 7.21 & 7.20 \\
\hline FFR & 0.36 & 6.10 & 8.80 & 8.78 & 8.85 \\
\hline Other & 91.10 & 86.88 & 84.49 & 84.01 & 83.95 \\
\hline \multicolumn{6}{|c|}{ Panel C: FC } \\
\hline $\mathrm{FC}$ & 63.40 & 56.90 & 54.04 & 52.04 & 49.66 \\
\hline FFR & 0.21 & 3.16 & 5.96 & 6.21 & 6.20 \\
\hline Other & 36.39 & 39.94 & 40.00 & 41.76 & 44.14 \\
\hline \multicolumn{6}{|c|}{ Panel D: FFR } \\
\hline $\mathrm{FC}$ & 8.92 & 12.72 & 15.03 & 15.58 & 13.41 \\
\hline FFR & 42.05 & 29.45 & 22.95 & 17.72 & 13.06 \\
\hline Other & 49.04 & 57.83 & 62.02 & 66.70 & 73.53 \\
\hline
\end{tabular}

Table 4: Variance Decomposition Results: Baa-Treasury Spread For each of the GDP, BFI, FC, and FFR variables, we decompose the variance of the forecasting error into its components due to FC, FFR, and other shocks. The first four columns show the decomposition for the forecast error at horizons from one to five years, while the last column has the unconditional variance decomposition. The results are from the baseline VAR model in which financial conditions are measured by the Baa-Treasury spread. The sample period is 1974Q2-2016Q1. 
Horizon

\begin{tabular}{|c|c|c|c|c|c|}
\hline \multirow{2}{*}{ Shocks } & \\
\hline & 4 & 8 & 12 & 20 & $\infty$ \\
\hline \multicolumn{6}{|c|}{ Panel A: GDP } \\
\hline $\mathrm{FC}$ & 12.93 & 12.76 & 12.59 & 13.32 & 13.56 \\
\hline FFR & 0.12 & 0.84 & 2.60 & 2.87 & 3.36 \\
\hline Other & 86.95 & 86.40 & 84.81 & 83.81 & 83.08 \\
\hline \multicolumn{6}{|c|}{ Panel B: BFI } \\
\hline $\mathrm{FC}$ & 17.53 & 23.63 & 23.08 & 23.64 & 23.68 \\
\hline FFR & 1.35 & 1.73 & 4.54 & 5.30 & 5.67 \\
\hline Other & 81.12 & 74.64 & 72.39 & 71.05 & 70.65 \\
\hline \multicolumn{6}{|c|}{ Panel C: FC } \\
\hline $\mathrm{FC}$ & 78.55 & 74.48 & 69.34 & 64.65 & 63.92 \\
\hline FFR & 0.21 & 1.12 & 6.27 & 6.69 & 6.92 \\
\hline Other & 21.23 & 24.41 & 24.39 & 28.66 & 29.16 \\
\hline \multicolumn{6}{|c|}{ Panel D: FFR } \\
\hline $\mathrm{FC}$ & 6.72 & 13.87 & 14.70 & 13.47 & 12.31 \\
\hline FFR & 42.34 & 23.55 & 17.90 & 15.43 & 14.40 \\
\hline Other & 50.94 & 62.57 & 67.40 & 71.10 & 73.29 \\
\hline
\end{tabular}

Table 5: Variance Decomposition Results: Post-1985 Sample For each of the GDP, BFI, FC, and FFR variables, we decompose the variance of the forecasting error into its components due to FC, FFR, and other shocks. The first four columns show the decomposition for the forecast error at horizons from one to five years, while the last column has the unconditional variance decomposition. The results are from the baseline VAR model in which financial conditions are measured by the excess bond premium. The sample period is 1985Q1-2016Q1. 
Horizon

\begin{tabular}{|c|c|c|c|c|c|}
\hline \multirow{2}{*}{ Shocks } & \\
\hline & 4 & 8 & 12 & 20 & $\infty$ \\
\hline \multicolumn{6}{|c|}{ Panel A: GDP } \\
\hline $\mathrm{FC}$ & 10.44 & 9.86 & 11.14 & 11.64 & 11.90 \\
\hline FFR & 11.47 & 13.00 & 12.87 & 13.11 & 13.11 \\
\hline Other & 78.09 & 77.14 & 75.99 & 75.26 & 74.99 \\
\hline \multicolumn{6}{|c|}{ Panel B: BFI } \\
\hline $\mathrm{FC}$ & 16.94 & 21.76 & 22.06 & 24.55 & 24.65 \\
\hline FFR & 0.95 & 5.31 & 6.97 & 7.02 & 7.12 \\
\hline Other & 82.11 & 72.94 & 70.97 & 68.43 & 68.23 \\
\hline \multicolumn{6}{|c|}{ Panel C: FC } \\
\hline $\mathrm{FC}$ & 87.78 & 80.44 & 75.91 & 74.94 & 73.89 \\
\hline FFR & 0.10 & 4.54 & 7.58 & 8.07 & 8.13 \\
\hline Other & 12.12 & 15.02 & 16.51 & 16.99 & 17.98 \\
\hline \multicolumn{6}{|c|}{ Panel D: FFR } \\
\hline $\mathrm{FC}$ & 4.49 & 18.47 & 22.45 & 19.58 & 14.16 \\
\hline FFR & 57.41 & 42.47 & 35.22 & 28.65 & 21.51 \\
\hline Other & 38.10 & 39.06 & 42.33 & 51.77 & 64.33 \\
\hline
\end{tabular}

Table 6: Variance Decomposition Results: Alternative Identification

Assumptions For each of the GDP, BFI, FC, and FFR variables, we decompose the variance of the forecasting error into its components due to FC, FFR, and other shocks. The first four columns show the decomposition for the forecast error at horizons from one to five years, while the last column has the unconditional variance decomposition. The results are from a variation of the baseline VAR model in which FFR precedes the FC excess bond premium variable. The sample period is 1974Q2-2016Q1. 


\section{Working Paper Series}

A series of research studies on regional economic issues relating to the Seventh Federal Reserve District, and on financial and economic topics.

The Urban Density Premium across Establishments

WP-13-01

R. Jason Faberman and Matthew Freedman

Why Do Borrowers Make Mortgage Refinancing Mistakes?

WP-13-02

Sumit Agarwal, Richard J. Rosen, and Vincent Yao

Bank Panics, Government Guarantees, and the Long-Run Size of the Financial Sector:

Evidence from Free-Banking America

WP-13-03

Benjamin Chabot and Charles C. Moul

Fiscal Consequences of Paying Interest on Reserves

WP-13-04

Marco Bassetto and Todd Messer

Properties of the Vacancy Statistic in the Discrete Circle Covering Problem

WP-13-05

Gadi Barlevy and H. N. Nagaraja

Credit Crunches and Credit Allocation in a Model of Entrepreneurship

WP-13-06

Marco Bassetto, Marco Cagetti, and Mariacristina De Nardi

Financial Incentives and Educational Investment:

The Impact of Performance-Based Scholarships on Student Time Use

WP-13-07

Lisa Barrow and Cecilia Elena Rouse

The Global Welfare Impact of China: Trade Integration and Technological Change

WP-13-08

Julian di Giovanni, Andrei A. Levchenko, and Jing Zhang

Structural Change in an Open Economy

WP-13-09

Timothy Uy, Kei-Mu Yi, and Jing Zhang

The Global Labor Market Impact of Emerging Giants: a Quantitative Assessment Andrei A. Levchenko and Jing Zhang

WP-13-10

Size-Dependent Regulations, Firm Size Distribution, and Reallocation

WP-13-11

François Gourio and Nicolas Roys

Modeling the Evolution of Expectations and Uncertainty in General Equilibrium

WP-13-12

Francesco Bianchi and Leonardo Melosi

Rushing into the American Dream? House Prices, the Timing of Homeownership, and the Adjustment of Consumer Credit

WP-13-13

Sumit Agarwal, Luojia Hu, and Xing Huang 


\section{Working Paper Series (continued)}

The Earned Income Tax Credit and Food Consumption Patterns

WP-13-14

Leslie McGranahan and Diane W. Schanzenbach

Agglomeration in the European automobile supplier industry

WP-13-15

Thomas Klier and Dan McMillen

Human Capital and Long-Run Labor Income Risk

WP-13-16

Luca Benzoni and Olena Chyruk

The Effects of the Saving and Banking Glut on the U.S. Economy

WP-13-17

Alejandro Justiniano, Giorgio E. Primiceri, and Andrea Tambalotti

A Portfolio-Balance Approach to the Nominal Term Structure

WP-13-18

Thomas B. King

Gross Migration, Housing and Urban Population Dynamics

WP-13-19

Morris A. Davis, Jonas D.M. Fisher, and Marcelo Veracierto

Very Simple Markov-Perfect Industry Dynamics

WP-13-20

Jaap H. Abbring, Jeffrey R. Campbell, Jan Tilly, and Nan Yang

Bubbles and Leverage: A Simple and Unified Approach

WP-13-21

Robert Barsky and Theodore Bogusz

The scarcity value of Treasury collateral:

Repo market effects of security-specific supply and demand factors

WP-13-22

Stefania D'Amico, Roger Fan, and Yuriy Kitsul

Gambling for Dollars: Strategic Hedge Fund Manager Investment

Dan Bernhardt and Ed Nosal

WP-13-23

Cash-in-the-Market Pricing in a Model with Money and

Over-the-Counter Financial Markets

WP-13-24

Fabrizio Mattesini and Ed Nosal

An Interview with Neil Wallace

WP-13-25

David Altig and Ed Nosal

Firm Dynamics and the Minimum Wage: A Putty-Clay Approach

WP-13-26

Daniel Aaronson, Eric French, and Isaac Sorkin

Policy Intervention in Debt Renegotiation:

Evidence from the Home Affordable Modification Program

WP-13-27

Sumit Agarwal, Gene Amromin, Itzhak Ben-David, Souphala Chomsisengphet,

Tomasz Piskorski, and Amit Seru 


\section{Working Paper Series (continued)}

The Effects of the Massachusetts Health Reform on Financial Distress

WP-14-01

Bhashkar Mazumder and Sarah Miller

Can Intangible Capital Explain Cyclical Movements in the Labor Wedge?

WP-14-02

François Gourio and Leena Rudanko

Early Public Banks

William Roberds and François R. Velde

WP-14-03

Mandatory Disclosure and Financial Contagion

WP-14-04

Fernando Alvarez and Gadi Barlevy

The Stock of External Sovereign Debt: Can We Take the Data at 'Face Value'?

WP-14-05

Daniel A. Dias, Christine Richmond, and Mark L. J. Wright

Interpreting the Pari Passu Clause in Sovereign Bond Contracts:

It's All Hebrew (and Aramaic) to Me

WP-14-06

Mark L. J. Wright

AIG in Hindsight

WP-14-07

Robert McDonald and Anna Paulson

WP-14-08

On the Structural Interpretation of the Smets-Wouters "Risk Premium" Shock

Jonas D.M. Fisher

Human Capital Risk, Contract Enforcement, and the Macroeconomy

WP-14-09

Tom Krebs, Moritz Kuhn, and Mark L. J. Wright

Adverse Selection, Risk Sharing and Business Cycles

WP-14-10

Marcelo Veracierto

Core and 'Crust': Consumer Prices and the Term Structure of Interest Rates

WP-14-11

Andrea Ajello, Luca Benzoni, and Olena Chyruk

The Evolution of Comparative Advantage: Measurement and Implications

WP-14-12

Andrei A. Levchenko and Jing Zhang

Saving Europe?: The Unpleasant Arithmetic of Fiscal Austerity in Integrated Economies

WP-14-13

Enrique G. Mendoza, Linda L. Tesar, and Jing Zhang

Liquidity Traps and Monetary Policy: Managing a Credit Crunch

WP-14-14

Francisco Buera and Juan Pablo Nicolini

Quantitative Easing in Joseph's Egypt with Keynesian Producers

WP-14-15

Jeffrey R. Campbell 
Working Paper Series (continued)

Constrained Discretion and Central Bank Transparency

WP-14-16

Francesco Bianchi and Leonardo Melosi

Escaping the Great Recession

WP-14-17

Francesco Bianchi and Leonardo Melosi

More on Middlemen: Equilibrium Entry and Efficiency in Intermediated Markets

WP-14-18

Ed Nosal, Yuet-Yee Wong, and Randall Wright

Preventing Bank Runs

WP-14-19

David Andolfatto, Ed Nosal, and Bruno Sultanum

The Impact of Chicago's Small High School Initiative

WP-14-20

Lisa Barrow, Diane Whitmore Schanzenbach, and Amy Claessens

Credit Supply and the Housing Boom

WP-14-21

Alejandro Justiniano, Giorgio E. Primiceri, and Andrea Tambalotti

The Effect of Vehicle Fuel Economy Standards on Technology Adoption

WP-14-22

Thomas Klier and Joshua Linn

What Drives Bank Funding Spreads?

WP-14-23

Thomas B. King and Kurt F. Lewis

Inflation Uncertainty and Disagreement in Bond Risk Premia

Stefania D’Amico and Athanasios Orphanides

WP-14-24

Access to Refinancing and Mortgage Interest Rates:

WP-14-25

HARPing on the Importance of Competition

Gene Amromin and Caitlin Kearns

Private Takings

Alessandro Marchesiani and Ed Nosal

WP-14-26

Momentum Trading, Return Chasing, and Predictable Crashes

WP-14-27

Benjamin Chabot, Eric Ghysels, and Ravi Jagannathan

Early Life Environment and Racial Inequality in Education and Earnings in the United States

WP-14-28

Kenneth Y. Chay, Jonathan Guryan, and Bhashkar Mazumder

Poor (Wo)man's Bootstrap

WP-15-01

Bo E. Honoré and Luojia Hu

Revisiting the Role of Home Production in Life-Cycle Labor Supply

WP-15-02

R. Jason Faberman 


\section{Working Paper Series (continued)}

Risk Management for Monetary Policy Near the Zero Lower Bound

WP-15-03

Charles Evans, Jonas Fisher, François Gourio, and Spencer Krane

Estimating the Intergenerational Elasticity and Rank Association in the US:

Overcoming the Current Limitations of Tax Data

WP-15-04

Bhashkar Mazumder

External and Public Debt Crises

WP-15-05

Cristina Arellano, Andrew Atkeson, and Mark Wright

The Value and Risk of Human Capital

WP-15-06

Luca Benzoni and Olena Chyruk

Simpler Bootstrap Estimation of the Asymptotic Variance of U-statistic Based Estimators

WP-15-07

Bo E. Honoré and Luojia Hu

Bad Investments and Missed Opportunities?

Postwar Capital Flows to Asia and Latin America

Lee E. Ohanian, Paulina Restrepo-Echavarria, and Mark L. J. Wright

WP-15-08

Backtesting Systemic Risk Measures During Historical Bank Runs

Christian Brownlees, Ben Chabot, Eric Ghysels, and Christopher Kurz

WP-15-09

What Does Anticipated Monetary Policy Do?

WP-15-10

Stefania D'Amico and Thomas B. King

Firm Entry and Macroeconomic Dynamics: A State-level Analysis

WP-16-01

François Gourio, Todd Messer, and Michael Siemer

Measuring Interest Rate Risk in the Life Insurance Sector: the U.S. and the U.K.

WP-16-02

Daniel Hartley, Anna Paulson, and Richard J. Rosen

Allocating Effort and Talent in Professional Labor Markets

WP-16-03

Gadi Barlevy and Derek Neal

The Life Insurance Industry and Systemic Risk: A Bond Market Perspective

WP-16-04

Anna Paulson and Richard Rosen

Forecasting Economic Activity with Mixed Frequency Bayesian VARs

WP-16-05

Scott A. Brave, R. Andrew Butters, and Alejandro Justiniano

Optimal Monetary Policy in an Open Emerging Market Economy

WP-16-06

Tara Iyer

Forward Guidance and Macroeconomic Outcomes Since the Financial Crisis

Jeffrey R. Campbell, Jonas D. M. Fisher, Alejandro Justiniano, and Leonardo Melosi

WP-16-07 


\section{Working Paper Series (continued)}

Insurance in Human Capital Models with Limited Enforcement

WP-16-08

Tom Krebs, Moritz Kuhn, and Mark Wright

Accounting for Central Neighborhood Change, 1980-2010

WP-16-09

Nathaniel Baum-Snow and Daniel Hartley

The Effect of the Patient Protection and Affordable Care Act Medicaid Expansions on Financial Wellbeing

WP-16-10

Luojia Hu, Robert Kaestner, Bhashkar Mazumder, Sarah Miller, and Ashley Wong

The Interplay Between Financial Conditions and Monetary Policy Shock

WP-16-11

Marco Bassetto, Luca Benzoni, and Trevor Serrao 